\title{
Testing the impact of direct and indirect flood warnings on population behaviour using an agent-based model
}

\author{
Thomas O'Shea, Paul Bates, and Jeffrey Neal \\ School of Geographical Sciences, University of Bristol, Bristol, UK \\ Correspondence: Thomas O’Shea (t.oshea@bristol.ac.uk)
}

Received: 1 November 2019 - Discussion started: 9 December 2019

Revised: 12 June 2020 - Accepted: 2 July 2020 - Published: 20 August 2020

\begin{abstract}
This paper uses a coupled hydrodynamic agentbased model (HABM) to investigate the effect of direct or indirect warnings in flood incident response. This model uses the LISFLOOD-FP hydrodynamic model and the NetLogo agent-based framework and is applied to the 2005 flood event in Carlisle, UK. The hydrodynamic model provides a realistic simulation of detailed flood dynamics through the event, whilst the agent-based model component enables simulation and analysis of the complex, in-event social response. NetLogo enables alternative probabilistic daily routine and agent choice scenarios for the individuals of Carlisle to be simulated in a coupled fashion with the flood inundation. Specifically, experiments are conducted using a novel "enhanced social modelling component" based on the Bass diffusion model. From the analysis of these simulations, management stress points (predictable or otherwise) can be presented to those responsible for hazard management and post-event recovery. The results within this paper suggest that these stress points can be present, or amplified, due to a lack of preparedness or a lack of phased evacuation measures. Furthermore, the methods outlined here have the potential for application elsewhere to reduce the complexity and improve the effectiveness of flood incident management. The paper demonstrates the influence that emergent properties have on systematic vulnerability and risk from natural hazards in coupled socio-environmental systems.
\end{abstract}

\section{Introduction}

Flood hazard, or flood incident, management is a challenge that incorporates aspects of the natural sciences (hydrology, ecology, etc.), the social sciences (economics, politics, psychology, culture, etc.), and engineering. It is important for the efficiency and efficacy of decision-making processes to recognise that decision-making during floods involves what has been termed "technical complexity" (Correia et al., 1998b). Specifically, this is the social response to the hazard, and it encompasses interactions between individuals; the diffusion of decision-making; and collective, during-event, behaviours (Larsen, 2005). This complexity cannot (theoretically nor physically) be eliminated when planning for flooding incidents (Assaf and Hartford, 2002; Bennet and Tang, 2017; Correia et al., 1998a; Dawson et al., 2011) and can be a threat to effective planning processes (Axelrod, 1970; Correia et al., 1998b). In a broader sense, this complexity is a measure of the scale of the interactions within the affected area, encompassing dynamic multi-scale interactions and adaptions between individuals, groups, infrastructures, government, and the economy, all contributing to the social, political, and physical aspects of flood hazard management (Dugdale et al., 2009; Fordham, 1992; IPCC, 2014; Kossiakoff and Sweet, 2002; Werrity et al., 2007; Wisner et al., 1994).

Recent decades have seen strong emphasis being placed on multi-scale, participatory methods for dealing with floods, resulting in a paradigm shift from flood defence to flood risk management (Assaf and Hartford, 2002; Dawson et al., 2011; DEFRA, 2007; IPCC, 2014; Wisner et al., 1994). Such participation means the inclusive involvement of individuals and multiple agencies in the processes of hazard management, policy implementation, and post-event recovery. This emphasis is logical in that it aims to incorporate, as far as possible, the requirements of all those involved in the hazard planning process across a scale hierarchy that passes from government bodies to emergency services and on to the affected individu- 
als themselves. The complexity of such an ideal becomes apparent given that the intricate natures of human environments and environmental dynamics are, to a large degree, perceived as independent, and that when the two come into contact complexity becomes amplified within a coupled socioenvironmental system. For example, between 2010 and 2015, UK Government policy for flooding underwent a transformation that sought to address some of the known complexities of flood incident management (DEFRA, 2007; Eberlen et al., 2017; Environment Agency, 2012, 2016). The UK Government's Department for Environment, Food \& Rural Affairs (DEFRA) national framework for flood management emphasises the importance of localised decisions about flood risk and makes suggestions for developing community-based solutions to manage flood risk on a finer spatial scale. This transformation emphasised the need for innovative new approaches to managing the localised risk of flooding. This was expected to provide the foundation for better management at the larger scale as "good practice" innovations spread across more communities. Thus, UK flood policy can be defined as moving from a top-down to a bottom-up approach, often referred to as "alternative action" (DEFRA, 2007; Kossiakoff and Sweet, 2002).

Whilst both top-down and alternative action bottom-up approaches will be likely to have divergent outcomes owing to the different emphasis each places on variables within their respective approaches, the shift towards a bottom-up strategy indicates an acknowledgement of the need for greater local participation in decision making - something that is difficult to achieve with the "black-box" forms of assistance seen in most top-down approaches (Sabatier, 1986). Conversely, to formulate an effective bottom-up approach, the dynamics of the individual base elements, which in this model are individual people and are termed "agents", must be specified to a relatively intricate degree of detail. This is because theory suggests that individual and grouped responses will have a significant influence on the dynamics that emerge at higher systematic levels; thus, accounting for as much detail as possible at the individual level will have a bearing on the detail that can be developed within the descriptions of the whole system (Bresser-Pereira et al., 1993; Müller et al., 2013). Here, it is believed that individual and grouped responses are defined by environmental, interpersonal interaction and interpretation (Alexander, 1980; Assaf and Hartford, 2002; Axelrod, 1970) and that these are characteristic behaviours of sub-systematic processes which are either not present or not considered in coarser, top-down models of physical process - despite potentially having a significant influence on the outcome of an event in which they are involved (Correia et al., 1998b).

Agent-based models (ABMs), defined as "a computational method for simulating the actions and interactions of autonomous decision-making entities in a network or system, with the aim of assessing their effects on the whole system" (Dawson et al., 2011), provide a potential means to characterise these interactions. Essentially, this is a form of computerised model capable of simulating the emergent behaviour of complex systems. In such models, individuals and organisations are represented as agents within a simulated environment (Railsback and Grimm, 2012). In recent years there has been a proliferation of ABM applications within the research community, and examples of these applications relevant to flooding encompass (i) the role of social media in flood evacuation processes (Du et al., 2017); (ii) human perception, understanding, and anticipation of flash floods (Morss et al., 2016; Narzisi et al., 2006); and (iii) the effectiveness of simultaneous and staged flood evacuation strategies (Chu, 2015; Dawson et al., 2011; Zarboutis and Marmaras, 2005). A key issue for such applications is the development of realistic flooding scenarios to drive the behaviour of the modelled agents.

Hydrodynamic models can produce this information so long as they are developed with high-quality terrain and boundary condition information (see e.g. Neal et al., 2012); however, thus far, ABM applications have not taken full advantage of the latest developments in flood inundation modelling. To date, studies that have driven an ABM with a hydrodynamic model are those of Dawson et al. (2011), Lumbroso et al. (2011), and Medina et al. (2016), with the coupled flood agent-institution modelling framework of Abebe et al. (2019) also providing mentionable overlap. The Dawson et al. (2011) example used a simple diffusive wave model that solves Manning's equation over a raster grid of cells; it was implemented within an ABM to simulate a coastal flood and showed considerable potential. However, this study initially coded the hydrodynamic model directly within the ABM meaning that it was not easy to take advantage of recent rapid developments in efficient numerical methods for solving the shallow water equations (Bates et al., 2010) or high-performance computing (e.g. Neal et al., 2010) architectures. The coding environment in an ABM framework can never be as computationally efficient as writing software in a compiler language; therefore, solving dynamical equations on fine grids with numerical methods can be extremely slow. In addition, the lack of coding flexibility within ABM frameworks means that one cannot create more sophisticated model structures, such as hybrid 1D-2D hydrodynamic models, that are required to simulate fluvial flooding in urban areas. The only reason to code the hydraulic model within the $\mathrm{ABM}$ is if the behaviour of the agents changes the development of the inundation. In this situation it would be necessary to have the agent behaviour and flood dynamics co-evolve during the simulation, and this two-way interaction can only be achieved by having the hydrodynamic model and ABM tightly coupled in the same code. However, this is typically not the case when the agents in the model represent the general public rather than specific flood management actors, and for this situation a one-way coupling is sufficient. Writing a hydraulic model within the ABM framework for these cases 
has no advantages, and for many (perhaps most) flood types it leads to quite a few constraints.

As a result, in the "tightly coupled" approach of Dawson et al. (2011) the computational costs were high, and this limited the domain size and resolution of the modelling that could be undertaken. Instead of directly embedding the hydrodynamic model within the ABM, a more pragmatic solution when considering agents whose behaviour cannot affect the flood evolution is to indirectly couple a separate (and highly optimised) hydrodynamic model with an existing ABM framework. This allows each code to be properly optimised for the task it performs and enables each to be more easily updated as new methods become available. This is the approach taken here: we develop a coupled hydrodynamic model-agent-based model framework (hereafter termed a hydrodynamic agent-based model, or HABM) and use this to address two currently unresolved questions relating to flood evacuation warnings. These two specific questions are as follows:

1. During a flood, does the site-specific urban topography and morphology change the optimum evacuation warning strategy?

2. Do people (agents) respond better to direct or indirect (word of mouth) evacuation warnings for a flood event?

To date, research on flood warnings and evacuation has examined the challenges and changes in thinking required to tackle the paradox of flood "control" (Wisner et al., 1994, chap 6), the dynamic approaches required to address different forms of flood event (Barendrecht et al., 2017; Dawson et al., 2011; Gilligan et al., 2015; Smith and Tobin, 1979), and the roles of individuals and groups in flood warning and evacuative scenarios (Haer et al., 2016a, b; Correia et al., 1998b). However, thus far, little work has been conducted on whether evacuation strategies need to be tailored to the specific geographical setting or on whether different modes of communication (direct or indirect) affect the evacuee's response. Answering these questions is important if effective warning strategies for specific places are to be developed.

More broadly, answering these two questions encompasses the process of implementing alternative actions these rely on positive social participation (diffusion of ideas and their implementation), and they require broader acknowledgement of, and a specific approach to addressing, the associated socio-environmental complexity (Wisner et al., 1994; Wong and Luo, 2005; Zarboutis and Marmaras, 2005). The HABM framework enables us to properly explore the systematic, cross-scale sensitivity of social complexity to the physical flood phenomena and shows where the loci of vulnerability are within an affected system. Therefore, the goal of HABM use for this study is not to eliminate complexity from consideration but rather to harness it as a complement to more specific physical considerations within comprehensive hazard management strategies. This is tested by apply- ing it to a test case in Carlisle, UK. The overall aim is to offer an assessment of the value of alternative actions within flood hazard management as a whole (Dawson et al., 2011; Müller et al., 2013).

\section{Methods}

\subsection{Study area}

Carlisle (Cumbria UK), specifically the approximate $10 \mathrm{~km}^{2}$ study area of the city illustrated in Fig. A1, is a flood prone city with a history of contemporary study (Correia et al., 1998a; DEFRA, 2007; Environment Agency, 2006, 2012, 2016; Horritt et al., 2010; Neal et al., 2009, 2013). Notable flood events have affected the city since 1700 , with the recent 2015 flood event having been referred to as "unprecedented" in scale due to the river Eden's flood level rising $0.6 \mathrm{~m}$ above the previous record flood level from 2005. The location of the city at the confluence of the rivers Eden, Caldew, and Petteril means it is a useful source of data for hydrological research. As the county town of Cumbria, with a total population of 108000 , Carlisle is a location of significant social scale whilst also offering a case study which is suitably complex to develop new insights through modelling and simulation.

The 2005 event affected approximately 1865 properties and led to the loss of three lives. The event had an estimated annual exceedance probability (AEP) of $0.59 \%$ ( 1 in 170-year return period) and was a seminal event in that it prompted significant investment in the city's flood defences. The 2005 LISFLOOD-FP data set (Horritt et al., 2010) provides a robust and reliable foundation on which to build the agent-based component of the coupled model. This data set, which was used for the model simulation, consists of a series of input files including raster grids of floodplain friction coefficients and elevation heights in 2D, ARC-ascii format, boundary identification, time-varying boundary conditions, and hydrodynamics. Since 2005, Carlisle has been subjected to further large flood events in 2009 and 2012 with the mitigative measures deployed post-2005 successfully curtailing the impact of these. Furthermore, the 2015 event, overtopped the new defences and has led the Environment Agency to produce the Cumbria Flood Plan. A novel feature of this is that it introduces and promotes community-based flood resilience measures on a large scale for the UK. It is the essence of these measures that prompted the development of the coupled model with a view to better understanding the dynamics on which these measures were based (DEFRA, 2007; Dugdale et al., 2009; Environment Agency, 2006, 2012, 2016).

\subsection{The flood modelling component: LISFLOOD-FP}

For a viable exploration of different individual responses to flooding, detailed, accurate, and dynamic simulations of the flood at Carlisle were required. LISFLOOD-FP (Bates and 
De Roo, 2000; Bates et al., 2010; Neal et al., 2009, 2012) is a 2D hydrodynamic model specifically designed to simulate floodplain inundation in an efficient manner over complex topography, as is the case in urban areas. It is capable of simulating grids of up to $10^{7}$ cells for dynamic flood events with airborne laser altimetry defining the digital elevation model (DEM) of the affected area. From this, the LISFLOOD-FP model can accurately simulate the dynamic propagation of flood waves by predicting water depths in each grid cell through a series of time steps as well as over the complex topographic forms within floodplains. The ABM element of the coupled model can then operate from this reliable foundation using the model output as a boundary condition; this enables the exploration of different hypotheses for social reactions and responses to the detailed, accurate, and dynamic physical outputs generated by LISFLOOD-FP by adding the related elements of policy and systematic change (Wheater, 2006; Wilson and Atkinson, 2005). Whilst LISFLOOD-FP was the chosen hydraulic model for the HABM, similar 2Dhydraulic models could resolve flow problems to similar degrees of accuracy, and this would mean that these alternative models could be utilised in place of the LISFLOOD-FP within the HABM modelling framework (Hunter et al., 2008; Landstrom et al., 2011; Neal et al., 2012).

\subsection{The social modelling components: HABM and NetLogo}

With LISFLOOD-FP producing an accurate representation of the flood at Carlisle, the related elements of flood incident policy options and agent behaviour were implemented through the separate ABM program of NetLogo (Railsback and Grimm, 2012; Wilensky and Rand, 2015). The HABM (Figs. 2, 3, and A2a-c) uses water depth output files from the LISFLOOD-FP at each model time step within a simulated version of the affected area (Fig. A2a-c). For the simulation of the Carlisle study area, a DEM, identical to that used by LISFLOOD-FP as an input data set, was used to provide a realistic topography of the flood-impacted area in NetLogo (NetLogo, 1999; Wilensky and Rand, 2015). In addition to the simulation of the flood event and physical landscape, NetLogo was used to generate a virtual population of agents to occupy the virtual version of Carlisle. Using a pseudo-random number of generator and deterministic agent scheduling algorithms directed through probabilistic routines (Correia et al., 1998b; Wilensky and Rand, 2015; Wong and Luo, 2005), this then simulated the population's interaction with the environment and the response to the flood event. This simulated interaction allows the possibility of identifying emergent properties likely to arise at the complex interface between the social and environmental systems. These emergent properties have a significant impact on objective 1, in that they occur subtly and at locations that significantly influence human responses within the coupled physical and social systems. This significance is found in the HABM's ca- pacity to reveal systematic emergent phenomena through the simulated co-evolution of a socio-environmental system, operating here through a flood event that has impact upon the basic daily routine (Fig. 1) and the complex co-existent entities, i.e. the more complex, responsive configuration of evacuating groups (Figs. 2,3). This then has a further impact on hypotheses regarding risk, vulnerability, and resilience, with the HABM providing an opportunity to analyse and evaluate these terms from a sub-systematic perspective. Here, "subsystematic" is a term used to describe the development of individual (micro) to community (meso) level characteristics in response to the flood onset, with greater scope than has previously been possible with traditional approaches to flood incident management (Borshchev and Filippov, 2004; Chen and Zhan, 2008; Gilbert and Troitzsch, 2005; Guo et al., 2008; Guyot and Holiden, 2006; Landstrom et al., 2011; Namatame and Chen, 2016; Sanders and Sanders, 2004; Srbljinović and Škunca, 2003; Wei et al., 2003).

\subsection{The enhanced social modelling component: Bass model}

For objective 2 of this paper, and in planning for effective flood impact management on a broader scale, we must incorporate elements from a whole range of activities (Axelrod, 1970; Barendrecht et al., 2017). These include the spatial and temporal variations in phenomena (flooding in this instance), the non-linear relationship between small perturbations at a sub-systematic level and large knock-on effects at a system-wide scale (the macro-level), and the understanding that these effects can extend beyond the physical impacts of the phenomena and change social behaviours and routines within an affected area, thereby changing the characteristic function of the system as a whole. This suggests that objectives 1 and 2 are intimately connected; thus, there is a need to consider the social dynamics and reflexive nature of the human system in response to the flood event within the framework of the hazard system to determine the sensitivity of the incident management response (Davies, 1979). To better understand this relationship between the human system and environmental phenomena (Fig. 1), the ABM was used to provide choices to the simulated agent population of Carlisle as part of a synthetic daily routine (Figs. 2, 3), further details of which are found in Sect. 3 of this paper. These agent choices and the routine were combined to synthesise the dynamics of the socio-environmental interface, and, from this, estimates were made regarding the influence that agent choices have on the characteristics of the system being simulated. In the Carlisle HABM, the agents were given the choice of carrying out their normal, linear, routine during the flood scenario; of becoming warned and taking immediate action to evacuate; or of assessing this warning based on social interaction with other agents in the immediate vicinity and then acting post-interaction (Fig. 4). The scenario of becoming warned and evacuating immediately is used in the 
HABM to reflect the government policy instruction of "what to do in a flood scenario" in the most direct form. Within the model (DEFRA, 2007), this instruction is programmed as "pre-preparedness" and it describes an adoption and undertaking of actions beyond the "normal" daily routine, both modelled and real (Chen and Zhan, 2008; Chu, 2015).

The Bass diffusion model provides a tool for interpreting the impact of these choices and actions, by representing agents who adopt certain actions at a given time. The model, originally conceived for marketing economics, is used to inform understanding of the diffusion of frequently purchased or "adopted" products, and it is based on a principle derived from the following relationship (Bass, 1969):

$\frac{f(t)}{1-F(t)}=p+\frac{q}{M}[A(t)]$.

This states that "The portion of the potential market that adopts at time $t$, given that they have not yet adopted, is equal to a linear function of previous adopters" (Bass, 1969; Davies, 1979). The basic premise of the model provides insight into interaction between adopters of the "product" within a population; it then classifies these adopters as "innovators" or "imitators". In the HABM, the "material product" concept of the Bass model is replaced with the a priori product of "knowledge" regarding an imminent flood event - this is to say that agents within the model can simply be set to act out evacuative measures immediately at the start of the simulation and at all of the time steps leading up to the flood inundation, if they choose to stay. These "innovative" agents are also freely able to communicate these measures to proximal neighbouring agents, who can then choose to imitate these informed agents or carry on with what they are doing. It should be stated that the sociological dynamic of innovation and imitation is proliferated within the model by communication between agents who are proximal; therefore, this simple binary distinction could be regarded as a potentially useful one for representing the apparently complex communication dynamics of a social system in a relatively simple manner.

In the specific instance of the HABM, the innovators are set as pre-prepared prior to the flood simulation onset and the imitators are those who would not be prepared, but who are given the choice to adapt their routine at each time step, based upon contact with the innovators. This situation, describing people who are in possession of knowledge regarding the flood event and then communicate it to those who are not, could have an impact on all aspects of response and evacuation, as it is a crucial component of the boundary between the processes of warning and response (Axelrod, 1970; Chen and Zhan, 2008; Chu, 2015). With specific reference to the Bass model terminology, there are three parameters (or representative coefficients), that define the compatibility with the HABM:
- $(M)$ - the potential "market", which refers to the ultimate number of potential adopters, i.e. the population. This constitutes the number of members of the social system in which word-of-mouth communication from past adopters is the driver of new adoptions. The Bass model assumes that $M$ is constant, although in practice and over longer periods, $M$ is often slowly changing according to population change and product memory.

- $(p)$ - the coefficient of innovation, so-called because its contribution to new adoptions does not depend on the number of prior adoptions. Since these adoptions are due to some influence outside the social system, the parameter is also called the "parameter of external influence".

- $(q)$ - the coefficient of imitation has an effect that is proportional to cumulative adoptions $A(t)$, implying that the number of adoptions at time $t$ is proportional to the number of prior adopters. In other words, the more that people talk about a product, the more other people in the social system will adopt it. This parameter is also referred to as the "parameter of internal influence".

The other variables in the Bass model relationship and calculated from $M, p, q$, and $t$, are as follows:

- $f(t)$ - the portion of $M$ that adopts at time $t$,

- $F(t)$ - the portion of $M$ that have adopted by time $t$,

- $a(t)-$ the adopters (or adoptions) at $t$,

- $A(t)$ - the cumulative adopters (or adoptions) at $t$.

The outcomes of the coupled application of these three components (Sect. 2.1-2.3) towards the two objectives are further illustrated in Sect. 4 and are discussed further in Sect. 5.

Of further interest here is how to qualify the communication taking place within the HABM. In sociological terms, the imitative process involved is broadly one of inter-agent communication and collective response. According to the sociologist Gabriel Tarde and his laws of imitation (Tarde, 1903), as applied to "groups of people", innovations must undergo a process of diffusion over time to gain a foothold and become a component in the decision-making process linked to the innovation, be this adoption or rejection. The process outlined by Tarde (1903) involved in the diffusion of innovation has undergone some revisions in the decades since being first proposed and can now be defined through the following five steps:

- first knowledge,

- attitude formation,

- adoption or rejection,

- implementation, 
- confirmation of the decision.

Via the Bass model, the HABM for Carlisle allows a simulated engagement with the first four steps of the process from Tarde (1903), with the fifth being confirmed in the representation of the first four activities as the simulation advances over time. This interpretation of social imitation and adoption was used as a basis for investigating the influence of these processes in an event where time is relatively constrained and the stakes of action are high, such as during a flood onset. The values for this process of adoption were taken from the change in overall unprepared population in Carlisle transitioning to a prepared state based upon contact with a pre-prepared, or innovative, agent. This transition was represented by the percentage of the population in possession of the appropriate knowledge for effective flood evacuation who then reported this change back as an agent-orientated change of state throughout the simulation of the flood. This rate of change of state is then fed into the Bass model functions to produce diffusion curves like those seen in Fig. 4a and $\mathrm{b}$ and discussed in further detail in Sects. 4 and 5.

\section{Core model construction and system dynamics}

Given the complexity caused by the incorporation of these diverse elements within considerations of a flood hazard system, the benefits of a standardised flood incident management strategy based on an understanding of these dynamics might not be immediately apparent. Further management of complexity might necessarily arise through the required interactions between the individuals and organisations who might very well have conflicting interests linked to contrasting elements in their expertise or experience (Hart et al., 1968; Hornor, 1998). Furthermore, the feedbacks within a flood hazard system, particularly an urban one, can lead to a spectrum of dampening and amplification of behaviours within the system, the dynamics of which could be influential on outcome, although difficult to account for in a standardised flood incident management strategy (Assaf and Hartford, 2002; Dawson et al., 2011; Rasmussen et al., 1994). It is here that the HABM concept reaches out to the concepts of phenomenology, post-structuralism, structuration theory, structural functionalism, and symbolic interactionism to inform the conception of a modelling framework that incorporates the important social notions of these disciplines and, thus, anchors the modelling element of the HABM to the cardinal philosophical and sociological concepts underlying it and the outputs produced. The appeal of this approach lies primarily in the novelty of the undertaking in addition to the application of concepts from disciplines such as sociology, philosophy, and psychology, which complement the model by offering access to new terminology and theoretical bases for better representing social systems, focussed on "relatedness" rather than "boundedness" between the dimensions and the whole (Alexander, 1980) within a coupled mod- elling framework. Here, the benefit of a more holistic representation can lead to the development of a more effective and holistic understanding of how to manage social dynamics, responses, and functions within physical models where they can have further impact on effective planning for and outcomes from the whole system and the components comprising that system (Smith and Tobin, 1979; Zarboutis and Marmaras, 2005).

With these details in mind, and as urban systems are the primary interest in this paper (Fig. 1), the first step beyond bringing together the initial HABM components was to devise a conceptual format that describes the key dimensions of the urban system within a parameterised and reproducible framework. In this paper they will be primarily referred to as "dimensions", alternatively they can be called "sets" or "centres" (Alexander, 1980), and can be broadly subdivided into three separate systems: environment, community, and built infrastructure (UNISDR, 2015; Wisner et al., 1994). Networks existing between these dimensions, resulting from the co-evolution of the dimensions, are characterised by the immediate practical and physical influence that each has on the behaviour of the other to create an operational whole. Conceptually, this is analogous to the notion of the Brunnian link in mathematics and the post-structural, psychoanalytical concept for experience or jouissance proposed by Jacques Lacan's Borromean rings construct in the 1970s (Zupančič, 2000). An urban system, concomitant with our physical perception and experience of it, can occur at the nexus of the topological sets illustrated in Fig. 1. Whilst these constituent dimensions could be deliberated in terms of scale, dynamic, or boundary and seemingly experienced separately from one another by individuals or groups, it is important to understand that the function of the urban system within the HABM framework arises in the form of the aforementioned Brunnian link for the present analysis. This is as an "extended and unbroken continuum of connections wherein the whole is necessarily unbroken and undivided" so that life may be supported, experienced, and proliferated therein (Alexander, 1980).

Specifically, this link is a mathematical and topological term used to describe the triviality and non-triviality of connection between the sets. As applied to the HABM system concept, when disconnected from the complete, interconnected, system set, the system no longer exists and cannot be experienced by people within it. Utilising the terminology applied within mathematical topology, the individual systems become "trivial" when disconnected from one another and "non-trivial" when all are in contact within the dimensions of the systematic whole. Thus, the individual systems are experienced in combination with one another, where the boundaries, existing between these systems, would not be as discrete as those shown in Fig. 1. This would suggest an overlap in the systems whereby experience and interactions between these systems and people (life) occurs at the nexus of the three. A simplified scenario to support this understand- 


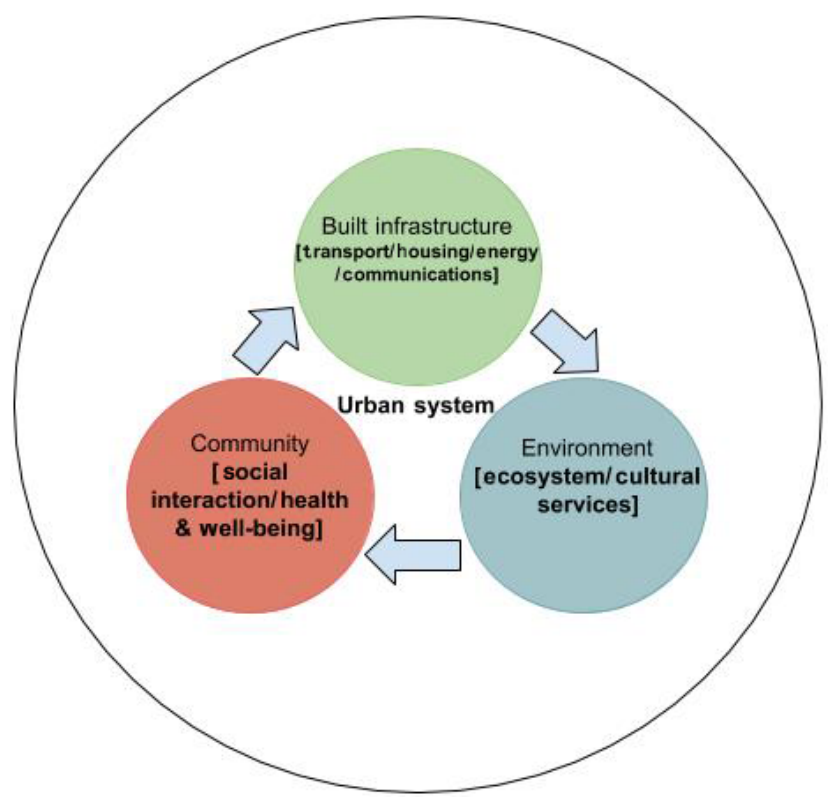

Figure 1. A simplified schematic illustrating the key centres of an urban system. Conceptualised from Axelrod (1970), Wisner et al. (1994), and the terminology given within the Sendai framework 2015-2030 (UNISDR, 2015).

ing for Carlisle would be one where there was a community requirement for an advance in built infrastructure as a response to perceived, or experienced, environmental risk from flooding - something which could be considered an emergent characteristic from the onset of the flood hazard system. Consequently, if the topologies of each of the three dimensions existed separately, and not connected in a manner as suggested in Fig. 1, interactions between the elements of the three system sets, including the manifestation of physically hazardous phenomena, would not be possible (Alexander, 1980; Axelrod, 1970; Barendrecht et al., 2017; Du et al., 2017; Dugdale et al., 2009; Eberlen et al., 2017; Fordham, 1992; Guyot and Honiden, 2006; Holland, 2014; Liu et al., 2015; UNISDR, 2015).

Thus, the simulations of the dynamics of Carlisle's urban system for the HABM focused on establishing the linked characteristics between the three dimensions to model a nontrivial system. The use of an ABM enables this through a focus on the community dimension, via the simulation of activities and interactions which may then be used as metrics for change according to a specific environmental event, in this instance the 2005 flooding of the rivers Eden, Petteril, and Caldew. To perform these simulations, a correspondence between the conceptualised urban system, representing the three interlinked elements of Fig. 1 and the modelling framework illustrated in Fig. 2, was developed. Figure 2 is a schematic of this correspondence and represents the overlying workflow of the HABM for simulations of the 2005 Carlisle flood. The layout for this figure was used to support the workflow and model structure in relation to the effective representation of the urban system shown in Fig. 1, within the ABM platform. The layout of Fig. 2 is such that the structure of each set from Fig. 1 corresponds to the processes taking place in NetLogo to represent that set. In summary,

- the environmental set is simulated using the LISFLOOD-FP outputs and the site DEM,

- the built infrastructure is emulated using census data sets and street network information,

- the community or social set overlaps both the built and environmental systems and is driven by the agent-orientated, probabilistic choice and interaction flowchart illustrated in Fig. 3.

The details of the diagram in Fig. 2 are the cardinal NetLogo commands that overlap between the system sets and, therefore, enable the simulation of the three dimensions within the HABM. This establishes a tangible link between the conceptual complexity of the urban system experienced by people with that experienced by agents, who represent people, within the simulated version of the urban system. This transferral from a conceptual topological figure to a logical modelling schematic was an important step that was taken to link the modelling system to the physical system being modelled. Whilst the format presented in Fig. 2 is not particularly novel in the sense of workflow or process for an ABM, it is relatively novel in the sense of how it illustrates this link between a conceptual construct of a system (Fig. 1) and the workflow steps required in simulating this system and representing dynamics that can provide an analogue for events that occurred during an historical physical event, such as that in Carlisle during 2005.

Figure 3 further extends this conceptual approach through to the community element of the modelled system in offering simulated agents the choice to engage with a basic, probabilistic, daily routine within the simulated system as well as engage in emergency response actions following flood onset. This further enhances the realism of the simulated population of Carlisle and provides an analogue for how variations in the physical interaction with a flood might affect the evacuation response (Morss et al., 2016; Müller et al., 2013). The routine and decision tree format, formulated through the ODD (Overview, Design concepts, and Details) protocol (Wilensky and Rand, 2015), with a view to potentially producing emergent behaviour for the modelled system, was initially referenced from the synthetic daily routine and transport model used for simulating storm-surge evacuation by Dawson et al. (2011). The adopted elements of this routine were the basic formatting seen in Fig. 3, whereby probabilities were assigned to activities for the agents in the model. Of note here is that a discrete transport model was not included in this model for these initial findings, as it was felt 


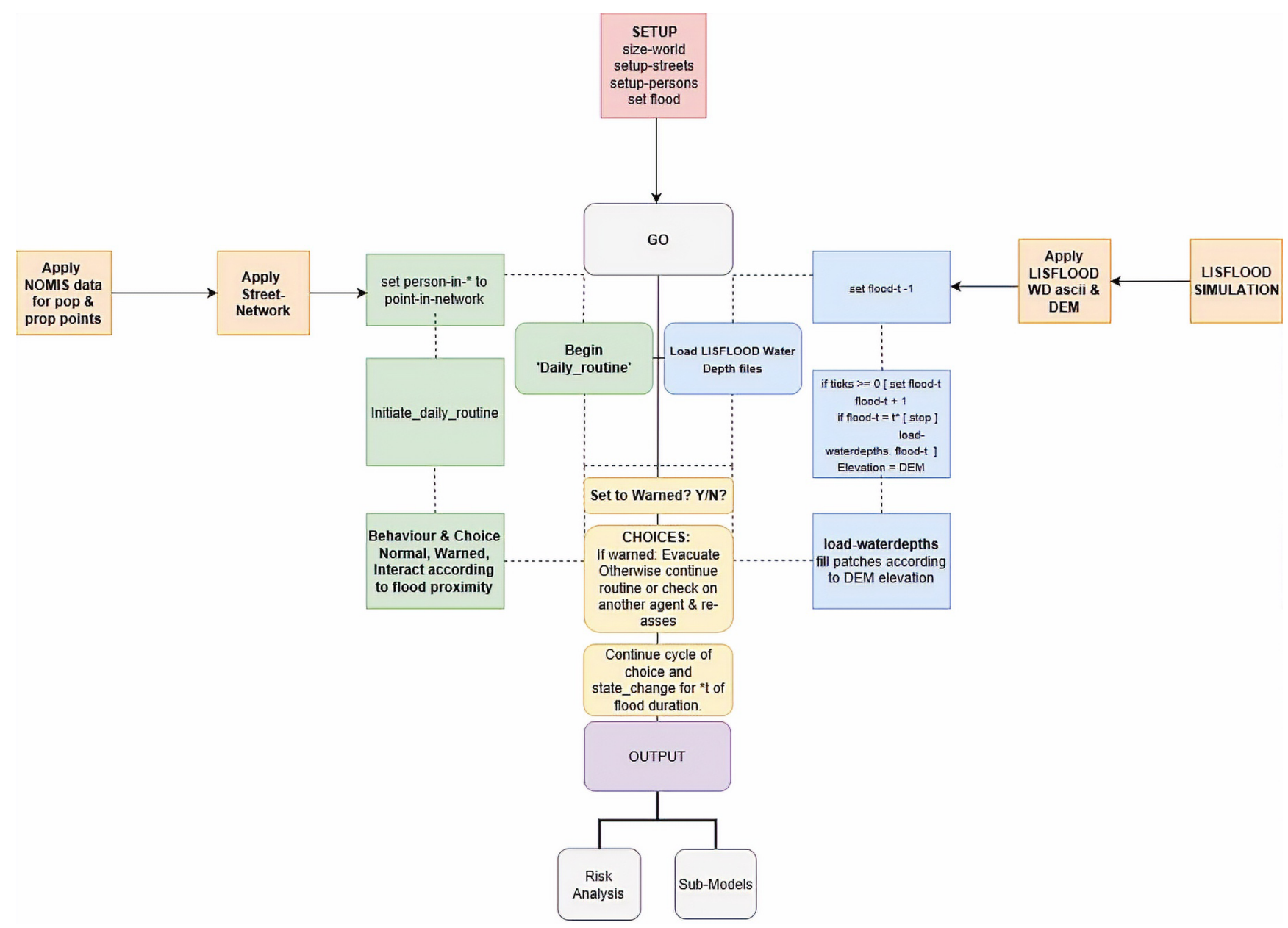

Figure 2. The core components of the HABM, an indication of the model cycle for these components, and the elements of the urban system (Fig. A1) that they demonstrate. The schematic follows a similar format to that of a Euler diagram (Whitehead and Russell, 1913), whereby the three centres of the urban system are shown to contain the respective components of the model representing their function within the HABM. These are (from right to left) built infrastructure, community, and environment.

that there had already been recent and significant advances in this area of interest (e.g. Coates et al., 2014; Pyatkova et al., 2019; Mostafizi et al., 2019). The activities of interest were engaged with on a point-to-point basis as the agents navigated through the simulated system of Carlisle until flood onset. With onset, the agents within the simulated system can then choose to engage with the emergency routine or continue with the elements of a daily routine until the next time step. As there is already a wealth of evidence available (see e.g. Assaf and Hartford, 2002; Barendrecht et al., 2017; Chu, 2015; Du et al., 2017; Dugdale et al., 2009; Eberlen et al., 2017) to suggest that the time of event onset is influential in event outcome, this time dependency was not implemented within the simulations for Carlisle. This choice was made in favour of developing streamlined simulations that emphasised agent-agent interactions between event onset and end. However, time dependency is something that is easily implemented within NetLogo if desired and was in- deed implemented in later iterations of the HABM for different applications. In addition to this agent-agent focus, agents that are not pre-prepared may also engage with pre-prepared agents in the model and initiate emergency action based upon their interaction, demonstrating a synthesised form of communication and response. The development of this step in the modelling procedure was crucial to allow the interpretation of the influence of an adopted policy directive on interagent interaction and the choices made during the onset of the flood event which may ultimately not be time dependent in nature (DEFRA, 2007; Landstrom et al., 2011; Liu et al., 2015; Morss et al., 2016; UNISDR, 2015; Waldrop, 1993).

The format of Fig. 3 was beneficial in this instance, as it offers a basic format for agents operating within the model of Carlisle - a format by which they can navigate along the street network in a manner reflective of what might be expected during an average day in Carlisle. The probabilistic format of the routine ensures that agents will be at specific 


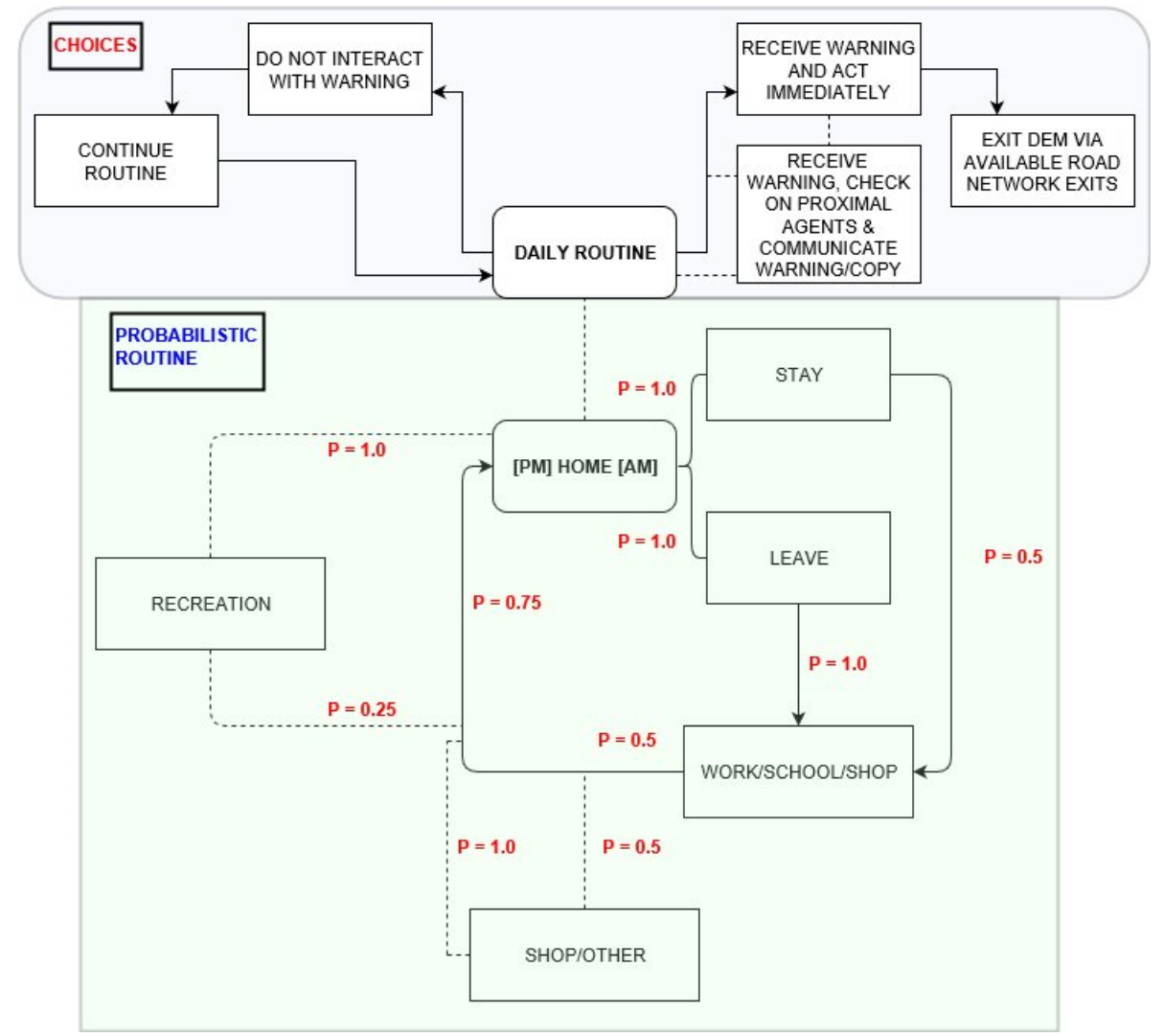

Figure 3. An overview of the agent choice and probabilistic routine tree used to guide agent processes through the simulated environment of Carlisle. Informed by reference to Bennet and Tang (2017) and Dawson et al. (2011).

points within the network at each time step. Whilst this attenuates the representative complexity of the model, it is believed that it offers enough complexity of choice and action to reflect the potential reality of a complex social and flood onset situation within Carlisle. The probabilities shown in Fig. 3 were adapted slightly from the original synthetic routine proposed by Dawson et al. (2011) to be more generalised and, for computational efficiency within NetLogo, were implemented to be acted out at each time step rather than continuously over flood onset.

In Fig. A2a-c, the product of the co-action between the components of Figs. 1-3 can be seen. These appendices illustrate the model in a preliminary state of simulation; thus, the full agent population is not in action. Whilst the largely autonomous processes of NetLogo, outlined in Sect. 2, influenced the extent to which the simulated agents engaged with the routine and the choices provided, the implementation of a routine acted to attenuate not only the representative complexity of the situation but also the outright stochasticity of the NetLogo agents. This means that whilst the agents would be interacting with "commands" e.g. "leave home point" or "stay at home point for $t(n)$ ", these commands are not too far removed from a realistic analogue of basic choices a human might make on a given day (Bernardini et al., 2017;
Chu, 2015; Dawson et al., 2011) with the possible actions of the daily and emergency routines being more reflective of the general and reactive behaviours expected during a flood onset (Du at al., 2017; Dugdale et al., 2009). The spatial distribution of the agent population within the HABM was informed with national UK Census statistics for Carlisle. However, as census data do not identify individuals against specific addresses, the distribution of agents within the simulated HABM environment was implemented in a slightly more utilitarian manner than the demographic-based distribution seen in Dawson et al. (2011) - by using a linear function of the population of Carlisle with agents being allocated to home points within the model according to building footprint (Bennet and Tang, 2017; Borshchev and Filippov, 2004; Dechter and Pearl, 1986).

In terms of the Bass model variables discussed earlier, $(M)$ is represented by 108000 agents (in the final simulations), which is the total population of Carlisle (Environment Agency, 2016); $(p)$, here, represents the $50 \%$ estimate by the Environment Agency (EA) for the population of Carlisle currently deemed as "signed up to flood warnings" or preprepared and in possession of the, defined within the HABM as innovative, knowledge to respond to the flood upon onset (Environment Agency, 2012); and the coefficient $(q)$ roughly 
equates to $30 \%$, which represents the one-third likelihood of those who encounter the innovators $(p)$ adopting the innovation as defined by the Bass model in a scenario where the rate of adoption between innovation and adaptation is linear or seamless (Bass, 1969). Despite this somewhat ideological perception of human communication (Jakkola, 1996), this rate of conversion was kept consistent in the instance of the Carlisle simulations as no evidence was found to suggest that social factors were present within Carlisle that would adversely affect it (widespread prejudice, social unrest, a despotic government etc.). In total, 200000 simulations were performed using this methodology within the NetLogo BehaviourSpace tool. These differed through scaling of prepreparedness between $0 \%$ and $100 \%$, and the outputs of interest from these simulations were the rate of change from an "unprepared" to an "evacuative" state, based upon agent contact and the number of potential casualties linked to the change in preparedness (\%). Finally, regarding the status of "potential casualties" within the HABM, this is a term and metric of the HABM used to describe agents physically impacted by the flood. This term does not account explicitly for "death", rather it is a measure of those agents who may become cut-off from a clear escape route or inundated during evacuative procedure; actual agent fatality was extremely rare during the simulations. The simulation of fatality was defined differently to physical fatality in that it was only presented when an agent's grid cell became inundated, to a third of an agent's height, for one time step, with all escape routes cut off (Assaf and Hartford, 2002; Landstrom et al., 2011; Roland and Moriarty, 1990).

\section{Results}

Within the appendices (Fig. A2a-c) there are examples of these simulated flood sequences for the 2005 Carlisle flood by the HABM, showing inundation areas and agent locations, both prior to the flood (Fig. A2) and at later stages (Fig. A2b, c) after flood onset and agents have been variously alerted. The time taken to model this process in NetLogo, over one complete event simulation, ranged from $45 \mathrm{~s}$ (2019) to $3 \mathrm{~min} 30 \mathrm{~s}$ (2017). The panels under the graphical user interface (GUI) within these appendices outline the basic controls for the model, whilst the charts on the right show model predictions for potential casualties in relation to populations and pre-preparedness, which is an a priori knowledge of the flood, as previously stated. These figures are representations of the modelled culmination of the concepts discussed in Sects. 1-3 and illustrated in Figs. 1-3 within the NetLogo interface.

In applying the Bass model to the Carlisle HABM, two diffusion curves were produced (Fig. 4a, b). These represent inter-agent communication regarding the adoption of policy instructions to either evacuate the area immediately, i.e. to adopt an innovative instruction, or to follow an imitative one after checking with nearby agents and only then deciding how to respond. The coefficient $(q)$ is typically represented by a much smaller value than $30 \%$ in traditional applications of the model (Mahajan et al., 1990). However, owing to the elevated risk involved in adopting, or not adopting, the product of evacuative knowledge during a hazard scenario, the traditionally small value of $(q)$ has been scaled up significantly. This is to represent a one-third likelihood $(\sim 30 \%)$ of those who encounter the innovator $(p)$ agents - receiving the flood warning by communication and adopting directly from them. Whilst this is a manipulation of the Bass model function, it remains consistent with the Bass model theory, stipulating that human adoption of a process or product is more likely to happen based upon internal systematic influence, or imitation, rather than through external influence on the social system, or by innovation. Wherein the available choices may be reduced to "yes", "no", and "maybe", probabilistically represented as roughly one-third each for a given scenario (Dechter and Pearl, 1986; Hart et al., 1968; Hornor, 1998; Mahajan et al., 1990; Massiani and Gohs, 2015; Sultan et al., 1996).

The fundamental difference between $(p)$ and $(q)$ is generated from this external-internal distinction. Aligning this further with the sociological notions of Tarde (1903), $(p)$ is a representation of an external factor that requires a change in the operation of the internal system dynamics $(q)$ over time, thought of as an attunement, harmonisation, or, in more traditional terms, as an acceptance. This means that for an innovative process $(p)$ to become a naturalised component of the internal system dynamics $(q)$, a significant amount of time may be required for innovation to lead to imitation when there is a risk involved (Wheater, 2006). In this application, the Bass model gives an indication of this duration based on the relative probabilistic magnitudes of $(p)$ and $(q)$ for a population of 108000 agents. The overall significance of this application is that it allows conclusions to be made as to how influential external policy protocols are for the population in relation to their internal "sense" during flood event response (Massiani and Gohs, 2015; Sultan et al., 1996).

The curves illustrated in Fig. $4 \mathrm{a}$ and $\mathrm{b}$ are the separate curves for the process of adoption based upon the optimised Bass model values for the coefficient of innovation $(p)$ at $50 \%$ and the coefficient of imitation $(q)$ at approximately $30 \%$ over 200000 simulations for the Carlisle model. The three separate lines are illustrations of the three different iterations of the model's standard differential equation as functions of continuous and discrete time (Bass, 1969). Correspondence between the curves represents an agreement between the model's functions and the data being plotted. Broadly, the curves show that the innovation of the external directive, seen in Fig. 4a $(p)$, is more effective at promoting an immediate process of evacuation, as a lower number of the simulated population changing state over time would suggest that a large proportion of the original innovators choose to act in the early onset of the flood and evacuate the area without 

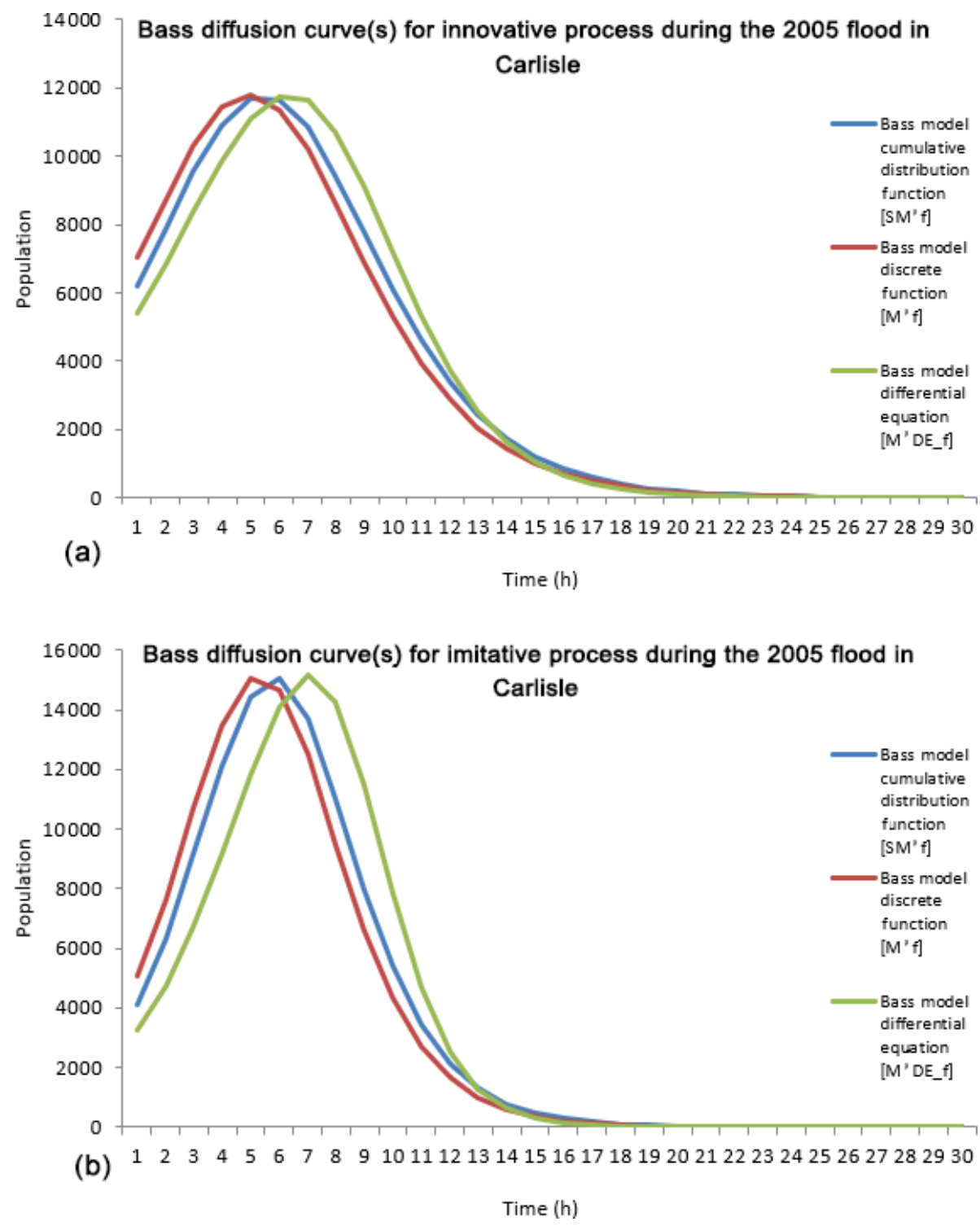

Figure 4. Example Bass diffusion curves for (a) p, or innovation, and (b) $q$, or imitation, at Carlisle during the 2005 flood. Shown is the type of knowledge and subsequent action taken based upon choices made by agents acting within the HABM.

hesitation. The negative aspect of this function is that there will be less agents available to communicate the innovative process and influence the less prepared agents; thus, this process of innovation will take longer to diffuse throughout the agent population leading to less agents taking appropriate action over a longer duration of flooding, thereby exposing themselves to potential danger.

The curve for Fig. 4b, $(q)$, is the internal function for evacuative measures, which is reliant on agent-agent interaction and suggests that the internal dynamics for the adoption of evacuative measures, that is to say the adoption of the same actions as the agency directive but not directly from the external directive (e-mail, text alerts etc.), according to communication and contact between agents, within the total flood affected population of Carlisle, is more influential over a shorter duration than the operation of $(p)$. The variance between the three lines would suggest that there is some disagreement between the baseline functions of the Bass model differential equation and those for discrete and continuous time functions for $(q)$; it is believed that this is likely related to the unusually high value attributed to the $30 \%$ likelihood of agents agreeing to imitate the innovative agents and become imitators as well as the general stochasticity related to the reliance on "proximal contact" for communication between agents, which is likely but not guaranteed in any situation - particularly in one as potentially frenetic as that involving a flood. 
This bridge between sociological and theoretical concepts of process diffusion, or between internal and external components, provides insight into the relationship that exists between policy and the responsive behaviour. Furthermore, the Bass model's use in the analysis of flood response dynamics is a broadly useful one, providing quantitative evidence of behaviour, in the form of diffusion curves (Fig. 4a, b) and, for the dynamics of agent communication during an event, thus implementing the sociological laws from Tarde (1903) into the modelling process. In addition, it represents both the innovative, i.e. individual response to policy direction, and the imitative processes related to this direction, which certainly have influence on the microscale, and potentially macroscale, human responses to flood events (Bernardini et al., 2017; Guyot and Honiden, 2006).

As the flood depths in the Carlisle data set were relatively shallow beyond the river channel during the early time steps, very few agents were presented with a potentially fatal scenario that they could not escape from, registering them as a potential casualty instead of a fatality. Broadly, a fatal scenario in this instance was determined by total cell inundation surrounding an agent and preventing them from leaving. Whilst there are examples of models utilising depth and velocity as determinants for a fatal scenario (Chen and Zhan, 2008; Chu, 2015; Dawson et al., 2011), these were not functions implemented in this preliminary model but were implemented in the later iterations of the HABM. Whilst the HABM should not be regarded as a full predictive tool, it does enable the visualisation of individual and group interactions, which might lead to potential casualties over repeated simulations. This is a valuable insight given that it is often difficult to identify comparable levels of detail from historical examples and their related data for microscale factors that are influential with respect to the event outcome. Illustrated in Fig. A3, once the overall preparedness of the agent population of Carlisle exceeds $30 \%$, either through increased social interaction or directly from policy instruction, the likelihood of casualties resulting from the flood scenario actually increases. This was an unexpected outcome and might, at first, seem counter-intuitive but is thought to be attributable to Carlisle's urban "fabric" (topography and morphology). When agents select to respond to the flood collectively and all at the same time, congestion of exit routes leads to an overall reduction in the movement away from flood inundated areas, thereby increasing agent exposure to the hazard (Wei et al., 2003; Werrity et al., 2007). This possibility is a valuable new insight produced by the HABM. Figure A3 illustrates the range of results from the 200000 simulations of the 2005 Carlisle flood. Across these simulations, the percentage of the population pre-warned of the flood event was varied between $10 \%$ and $100 \%$. The current DEFRA estimation for Carlisle is that $50 \%$ of the population ( 54000 people) are classed as prepared for a flood (termed "population warned" or "pre-prepared" in the HABM simulations). The population warned within the HABM will initiate evacua- tive behaviours, according to policy instruction, within the first hours ( $\sim 1-3$ time steps) of the flood inundation taking place and are able to communicate this action to surrounding agents from the outset of the simulation, largely bypassing the time required for the autonomous decision-making process during the event and engaging directly with the apparent agent preference for imitative behaviour.

To assume that a higher percentage of pre-prepared agents would lead to an overall reduction in potential casualties would be a logical assumption to make (Axelrod, 1970; Chen and Zhan, 2008; Dawson et al., 2011; Environment Agency, 2016). As highlighted by Figs. A3 and 6, overall potential casualties for the simulated population of Carlisle shows an increasing trend for higher percentages of prewarned agents, particularly above $80 \%$ preparedness. As already mentioned, this reflects the way in which Carlisle has been constructed around the confluence of the rivers Eden, Petteril, and Caldew. It highlights the deficiencies of this urban structure when a large inundation event forces significant numbers of agents to evacuate through a limited number of escape routes (Fig. 5; Gilligan et al., 2015; Sanders and Sanders, 2004). According to the HABM results, Carlisle's agent population has a distinct "preference" for evacuation to the south-west of the city, along the arterial A595. This preference was established through visual assessment of the simulations and was likely determined by the number of subroutes that had access to the A595 and that were not cut-off by flood waters. Indeed, the most densely populated areas of Carlisle are divided into four distinct areas by the three rivers shown in Fig. A1; therefore, this preferred escape route is only immediately available to those who are either preprepared, reside within the immediate vicinity of the A595, or who live or work to the west of the Eden and Caldew. As the flood progresses beyond the first 5-6 $\mathrm{h}$ of propagation, the number of escape routes diminishes, although the number of agents prepared to evacuate increases significantly. This creates a backlog in the system whereby more agents choose to stay in their immediate vicinity or to evacuate at the same time as everyone else, exacerbating the system congestion and increasing agent exposure to the flood inundation. Whilst agent choices do vary from simulation to simulation according the choices of their routine and the type of agents they make contact with, this pattern of evacuation occurs across the whole set of simulations and could, therefore, be taken as an indicator of likely choices made by the population of Carlisle if a flood happened today.

As is illustrated in Fig. 6, with less than $30 \%$ preparedness, agents within the HABM show a preference for evacuation away from Carlisle during the earlier stages of the flood onset; therefore, the social response to the flood is slow when there are fewer people in Carlisle to disseminate the message of evacuation. This finding further reinforces the results presented in the diffusion model (Fig. 4a, b). Without a threshold number of the population being aware of the impending flood, there is less likelihood of contact with unaware 


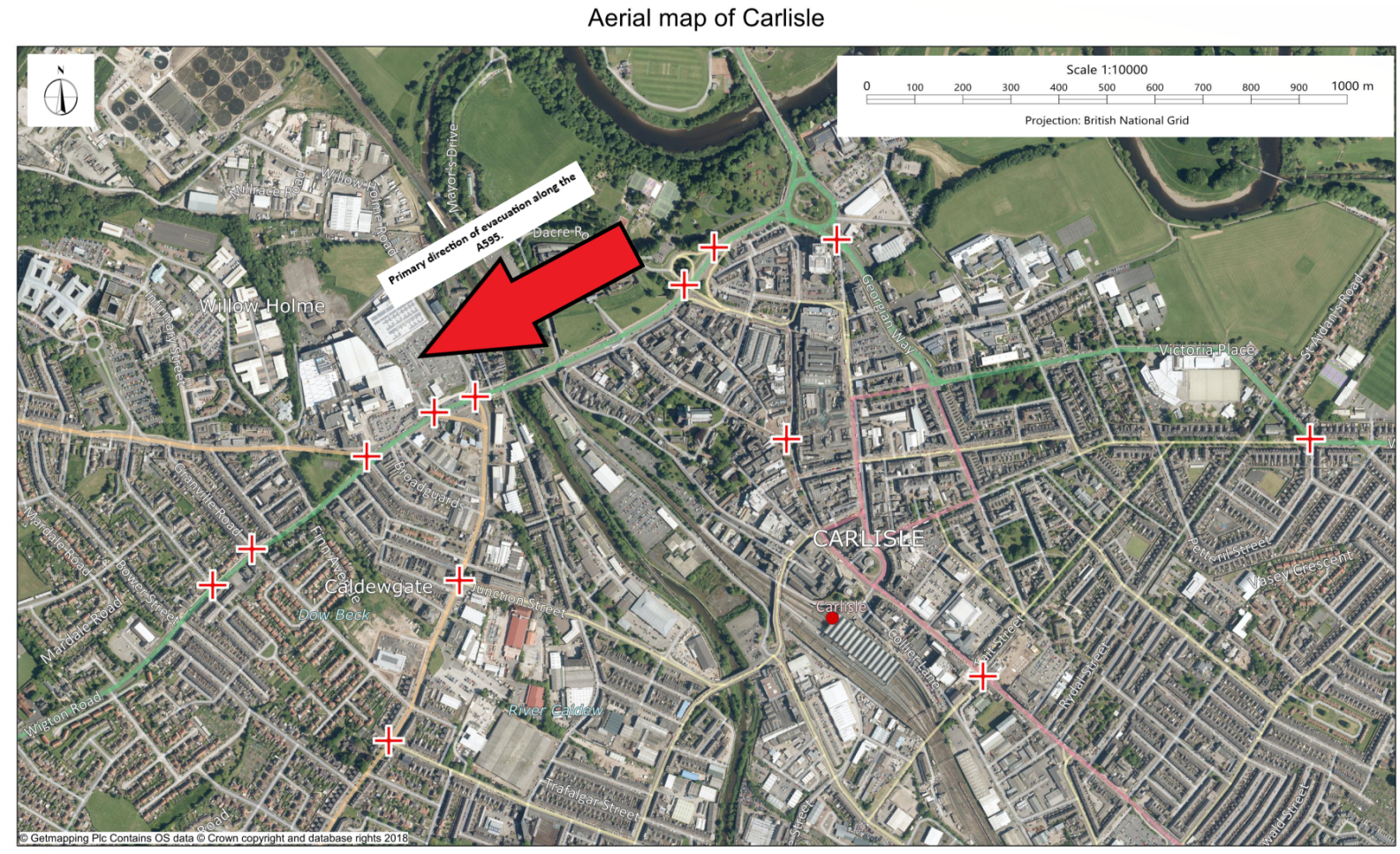

Figure 5. An aerial image of Carlisle illustrating the preferential direction for escape to the south-west along the A595. Further illustrated are the most prominent chokepoints (red crosses) for reduced evacuative flow of people between $80 \%$ and $100 \%$ preparedness. These points were identified from the HABM as the nodes in the street network overlay that have the most consistently high densities of agents throughout the range of simulations (contains OS data (C) Crown copyright and database right, 2019).

agents. This means that the response dynamics are more reliant on the innovative procedures of policy uptake and arbitrary choice, both of which are shown to be less likely to produce a successful evacuation outcome. The transition from a micro- to macro-level response, from individual agent interaction up to a large group response to changes in the environment, is realistically a much more complex process than that illustrated in the HABM model. Thus, as a starting point for testing hypotheses related to transitory-scale flood hazard response, it is a useful tool for exploring the related and inherent complexity of the socio-environmental interface present during a flood event (Wilensky and Rand, 2015; Wisner et al., 1994; Wong and Luo, 2005).

\section{Discussion}

From further interpretation of Figs. 4a, b, 5, 6, and A3 it is reasonable to infer that the agents within the HABM, representing the local population of Carlisle, demonstrate a further preference for basing their response to a flood event on interaction with their surrounding neighbours (a social response) rather than acting directly from policy instruction. The 2005 event in Carlisle significantly overtopped existing defences, meaning that local and possibly larger-scale man- agement actions would have been of little consequence to the event dynamics; thus, it is here that the social response becomes influential in the risk and resilience dynamics of the event (De Groot and Schuitema, 2012; Kinzig et al., 2013). With respect to these dynamics of response, the rate of innovation (Fig. 4a) impacts less of the Carlisle population over a greater duration compared with the rate of imitation (Fig. 4b). It is believed that this could be because there is a higher number of the influential (aware or pre-prepared) agents leaving the vicinity of the flood prior to, or in the early time steps of, flood onset; therefore, the message of adoption from these agents becomes less likely to diffuse through the rest of the population (seen in Fig. A2a-c). Conversely, when the remaining proportion of the population begin to experience the effects of the flood and a greater number of this population's daily routine becomes disrupted, a greater number of this population will transition to the choice scenario (Fig. 3) and begin checking with the agents around them regarding what an appropriate response will be. This proliferates the imitative process of evacuation and would therefore explain why the rate of imitation is more influential over a shorter period, particularly when the compact social network of Carlisle - facilitated by a relatively constrained urban topology and morphology - is considered. 


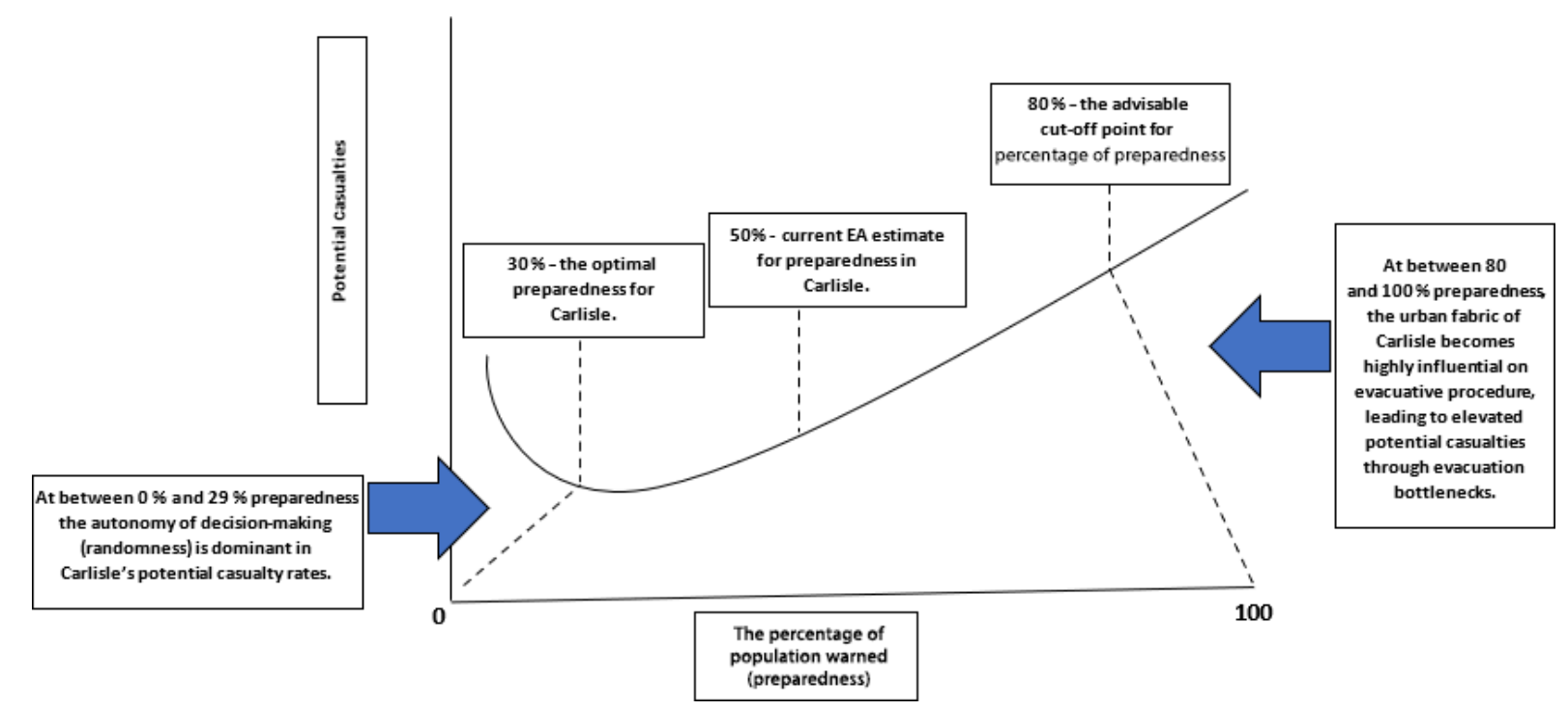

Figure 6. A representation of the key results shown in Fig. A3 and the concepts that can be associated with them. It is expected that these percentages will vary with model parameterisation and changes in the area modelled.

A likely explanation of the slightly better correspondence between the curves of Fig. 4a compared with Fig. 4b is that they represent a direct instruction at the outset of the simulation; thus, there is less time for choice to be considered, with agents taking direct action as soon as possible. The issue with this is that the agents carrying the innovative knowledge will encounter less agents as the event unfolds over time, having taken evacuative action from the outset and left the area where the rest of the agents may not have encountered the flood inundation yet and are therefore continuing with their daily routine. Consequently, when the function of $(q)$ is considered, a more effective and efficient process for diffusing the evacuative information amongst the modelled population of agents is seen. To understand why this is the case one must consider the dynamics at play in a broad sense: $(q)$ is a descriptor for internal influence and, within the HABM, is reliant on agent-agent interaction, whilst $(p)$ is the innovative directive from a distal governmental agency which is reliant on engagement from the population; thus, to simplify this process as much as possible for these simulations, this directive was designated as an instruction to "take evacuative measures immediately". Worthy of note here is that, for the applied parameters, the Bass model is considered a pessimistic forecasting tool with more optimistic alternatives, which have potential for application in similar scenarios, being based on the shifted Gompertz and Weibull distributions, both of which have superior forecasting and theory-testing capabilities but do not offer such a balance between normative and non-normative interpretation, necessary for this format of analyses, as is the case with the use of the Bass model (Jakkola, 1996).

Within the HABM specifically, the format for agent distribution and seeding is more generalised, and the framework of the daily routine is more direct, than in comparable models. This is, in some ways, a concession in relative precision, justified by the sustainable operation of the model within the NetLogo format (Rasmussen et al., 1994; Wilensky and Rand, 2015; Wong and Luo, 2005). Furthermore, with the primary application of this model being concentrated on the development of understanding regarding the complex nature of human interaction with the urban and natural environments, under extraordinary or unusual circumstance, the production of interpretable metrics using a new, interdisciplinary tool is considered to be a significant first step in enhancing understanding in this area. The general form of complexity explored in this paper has certainly been subject to greater scholarly interest in recent times, and this has been evident through the proliferation of publications on the subject and related phenomena, particularly during the last decade (Liu et al., 2015). As a result of this, complexity science has increasingly undergone a process of extension into quite different scientific fields (Alexander, 1980; Axelrod, 1970; Wilensky and Rand, 2015). This process, whilst a necessary element of scientific progress, has in some way acted to separate theory from application and has led to a diminished emphasis on cross-disciplinary applicability, leaving potentially useful scientific tools isolated or limited by the technological capability of the time. This has furthered the highly fragmented development of agent-based models and modelling frameworks (Axelrod, 1970; Müller et al., 2013; Namatame and Chen, 2016). These largely fall into one of two polar groups: those that overemphasise a very specific use through a reductive process of refinement to meet validative expectations and those that place themselves at the extremity of validation because of the physically unimaginable complexity that is being modelled (Ormerod and Rosewell, 2009). It is here, de- 
spite any shortcomings, that the value of the HABM is found - at the point of bifurcation between these groups (Assaf and Hartford, 2002; Eberlen et al., 2017; Guo et al., 2008; Liu et al., 2015; Morss et al., 2016; Correia et al., 1998b; Waldrop et al., 1993; Wei et al., 2003; Werrity et al., 2007).

The provision of a probabilistic framework (Fig. 3) for the "pseudo-random", this being a term which describes the large array of numbers underlying the agent's movements (i.e. leave, stay, etc.), within the model environment - which are effectively limitless but are also bounded by the fractal (self-replicating) "stochasticity" of the model layer implemented within NetLogo - has great importance for the general and transdisciplinary application of the methods in this paper. This is particularly the case in the absence of empirical certainty for how the real population of Carlisle might individually act on the day. However, the framework provides some necessary, general, parameters for human response in the event of a flood and, therefore, greatly reduces the possibility of an entirely chaotic modelling scenario, whilst also maintaining a realistic representation of choices that represent systematic functions of the community, infrastructure, and environmental dimensions within the urban and flood hazard system. Finally, it allows reproducibility for the HABM where components of future hydro-sociological models could simply be substituted for those of the HABM (Landstrom et al., 2011; Sabatier, 1986; Wong amd Luo, 2005).

In reality, the social elements of the complexity explored here are as unpredictable as they are dynamic; this challenges forecasting behaviours in addition to their understanding. As evidenced in this paper, the social elements are represented by many different participants who adapt and influence one another, interacting in intricate ways that continually reshape their individual and collective responses. When performed collectively, these interactions form systems which are characterised by multi-scale interactions between the microscale (individual) and the macroscale (demographic, economic, and governmental). The collective coalescence of multi-scale interactions have been termed "complex adaptive systems", and they have a significant underpinning from research focused on their interdisciplinary and methodological design so as to better understand the significant challenges presented by their complexity (Dugdale et al., 2009; Gilligan et al., 2015; Holland, 2014; Liu at al., 2015; Morss et al., 2016).

Ultimately, the design of "holistic risk management strategies requires an accurate understanding of the level of risk across the various layers of society. One important remaining limitation in our understanding of flood risk is the way individuals perceive and respond to risk. Even if we manage to model population density and flood inundation with increasing accuracy, assumptions about peoples' risk reducing behavior, willingness to relocate, and access to information play a key role in the actual level of risk" (Jongman, 2018, p. 2). Individual perception is an extremely complex phenomena and representing this from event and sys- tematic complexity is paramount for developing further understanding of the nature of the physical-social interactions discussed here, so that evacuations may be better organised and the greatest number of lives may be saved in the event of a complex event, like a flood (Barendrecht et al., 2017). Consequently, the non-linear characteristics associated with complex adaptive systems, including influential systematic processes such as heterogeneity, phase transition, and emergence, require that our methods, such as those illustrated in the HABM, also attempt to represent the general complexity of adaptive systems. Given that such systems exist as macro-networks of partially connected microstructures (fundamentally via individuals interacting in different groups which adapt to changes in the surrounding environment), the methods must then also include microscale models which are able to simultaneously simulate cross-scale operations, interactions, and responses amongst multiple participants (Assaf and Hartford, 2002; Dawson et al., 2011), to provide interested parties with access to more representative insights of what is and could be unfolding in reality.

Finally, during the 2005 flood, as modelled by the HABM for this paper, three deaths occurred. During the 2015 flood event in Carlisle, the river Eden exceeded the 2005 flood level by $600 \mathrm{~mm}$, yielding only one fatality but with a much greater economic impact (Environment Agency, 2016). Even with the generalised potential fatality metric implemented into the HABM, set as such due the low number of actual fatalities that occurred during the 2005 event, if the results of the model's simulations are to be believed, there is a much greater potential for a fatal impact within the flood inundation area than that which presented itself during the actual events of Carlisle in 2005 and 2015. Here, the true importance of the HABM and Bass model results is that they offer a counter-intuitive scenario to be further deliberated, one which could prove significant for flood hazard management in Carlisle and risk management overall.

\section{Conclusion and future development}

This paper began by proposing two specific questions:

1. During a flood, does site-specific urban topography and morphology change the optimum evacuation warning strategy?

2. Do people (agents) respond better to direct or indirect (word-of-mouth) evacuation warnings during a flood event?

These questions were formulated to explore the UK governmental shift towards alternative, bottom-up, action for addressing flood vulnerability and risk, as especially affected by agent response and urban morphology. These objectives simplify what is a very complex scenario; thus, with respect to this complexity, a methodological framework for addressing these two objectives was formulated and demonstrated, 
producing results via a coupled hydrodynamic and agentbased model: the HABM. This model was used to explore the complexity of human responses and behaviours during a flood event with a view to better specifying the two basic elements of the flood hazard system - a physical flood interacting with a human urban system. From this investigation, a range of implications were uncovered by the model simulations of response and behaviour. Based upon observation of these implications, the following practical recommendations can be made for flood warning delivery and strategy:

- Agents operating within a system of change show a preference for action via a socially imitative process as opposed to one which operates from innovation. This would suggest that bottom-up approaches towards warning and evacuation would benefit from incorporating measures that harness this understanding of group processes.

- Owing to the influence of site topography on the outcomes of social response, and the creation of potential congestion points within affected sites, a phased response to flood events should be an actionable option within flood warning strategy and delivery.

- During the process of issuing a flood event warning, the geography (topography and morphology) of the affected site can significantly influence the success or failure of the evacuative process; therefore, this influence should be given due attention during planning. This reaction phase involving the response and movement of people does not normally receive much attention and likely should.

- Whilst it might be a desirable goal to achieve $100 \%$ preparedness within a flood-prone area, the results from the HABM simulations suggest that this may not be necessary, or even desirable. Simulations support the idea that the $50 \%$ estimate of the EA for Carlisle is the best value for efficient evacuation, owing to the social dynamics and the topography of the site. The design of "optimal" impacts for ranging percentages of prepared people and for sites with differing layout and population dynamics needs to be critically considered in future flood response strategies.
There are significant questions that arise from these recommendations that require further analysis. Enhanced development of the HABM and the related themes will look to provide this further analysis in the form of the following:

- The nature of the agent decision-making process in locations where interaction is concentrated, e.g. is social response hastened where there is a higher population density?

- The nature of agent response with respect to the physical attributes of the flood event, e.g. attenuation of the flood hydrograph and variations in the flood volume influencing the process of evacuation.

- Different urban morphologies: will these give dramatically different results to those produced for Carlisle?

Whilst not a predictive tool, the implications of the results outlined herein, coupled with such future developments of the HABM, are useful in providing greater scope for including and quantifying relevant operative factors that are involved in flood vulnerability, risk, and resilience as related to urban systems. The HABM offers a dynamic method for simulating important actions linked to those where the agents themselves cannot affect the flood evolution, with the potential to enhance quantitative analyses in support of the decision-making process for flood hazard management. This paper demonstrates that such quantification can involve not only flooding itself but also potential human responses. These may exacerbate the risk if they are not accounted for during planning, or they may be diminished through improved response planning. Other hazard environments may similarly be analysed using the approach outlined here, providing many points of further discussion and consideration for stakeholders involved with risk assessment. The HABM can be a welcome and useful analytical tool for supporting and expanding on these points whilst moving forward. 


\section{Appendix A}

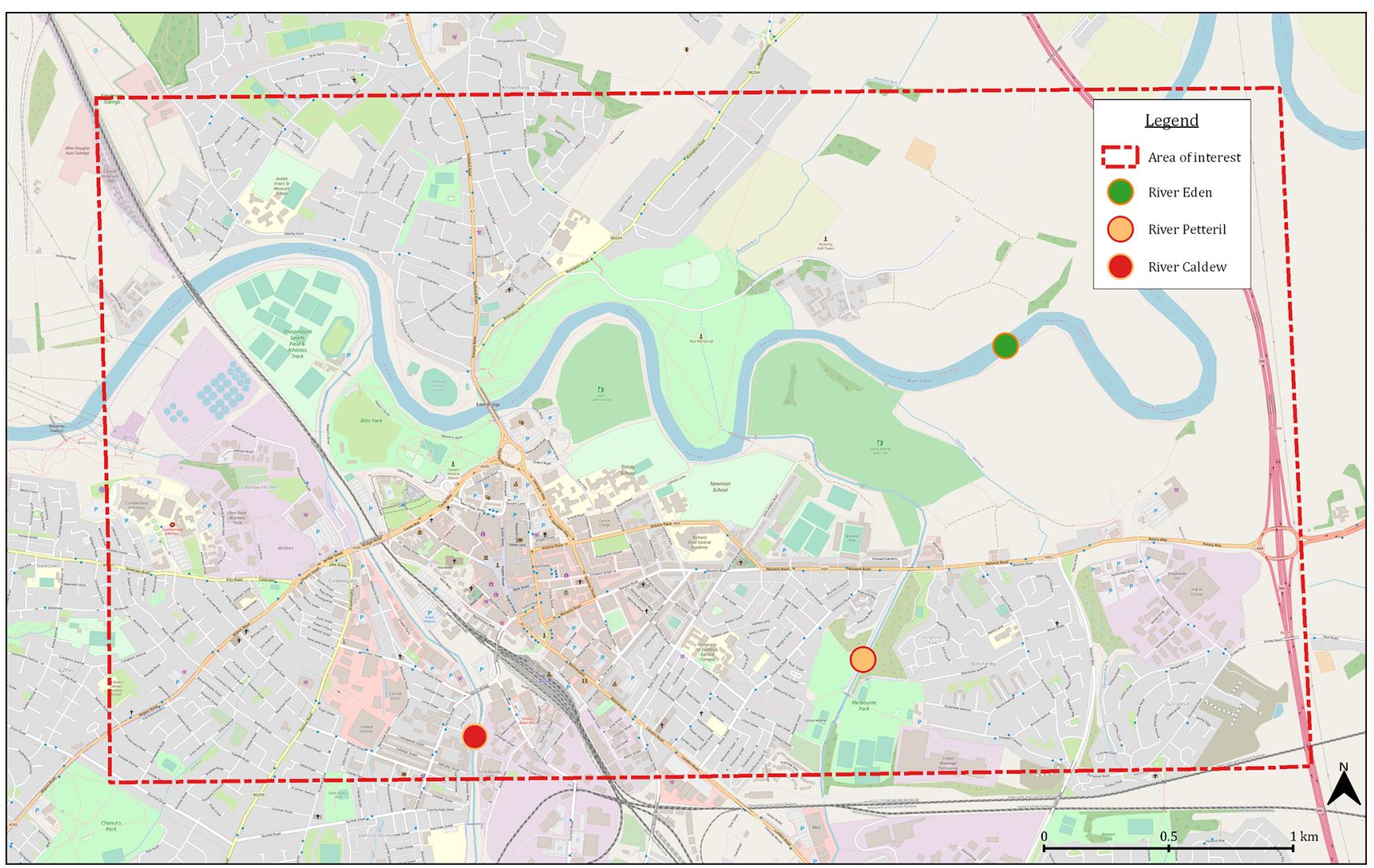

Figure A1. The total area of interest at Carlisle. An approximate area of $10 \mathrm{~km}^{2}$ was simulated in the HABM modelling runs (QGIS Development Team, 2020). 

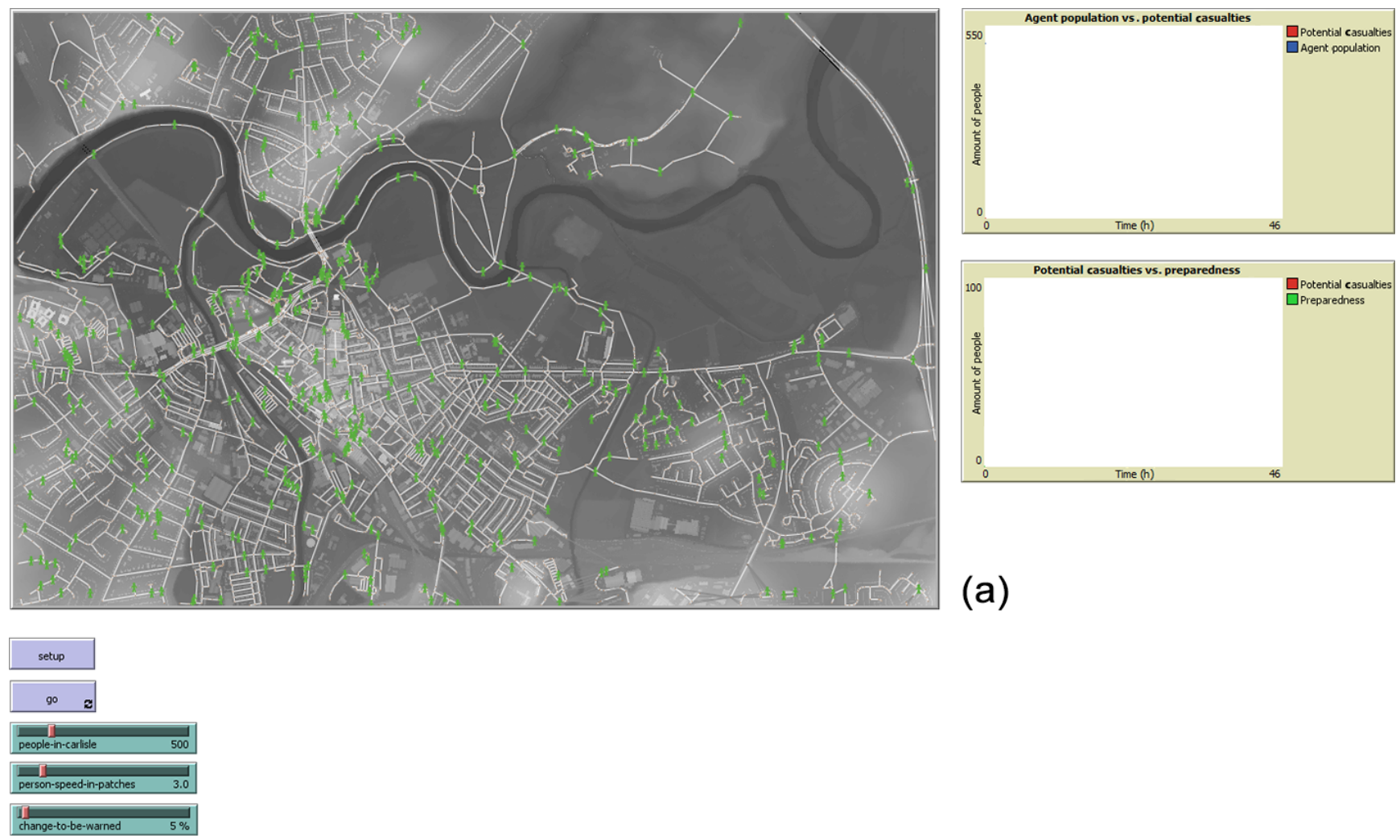

(a)

Figure A2. 

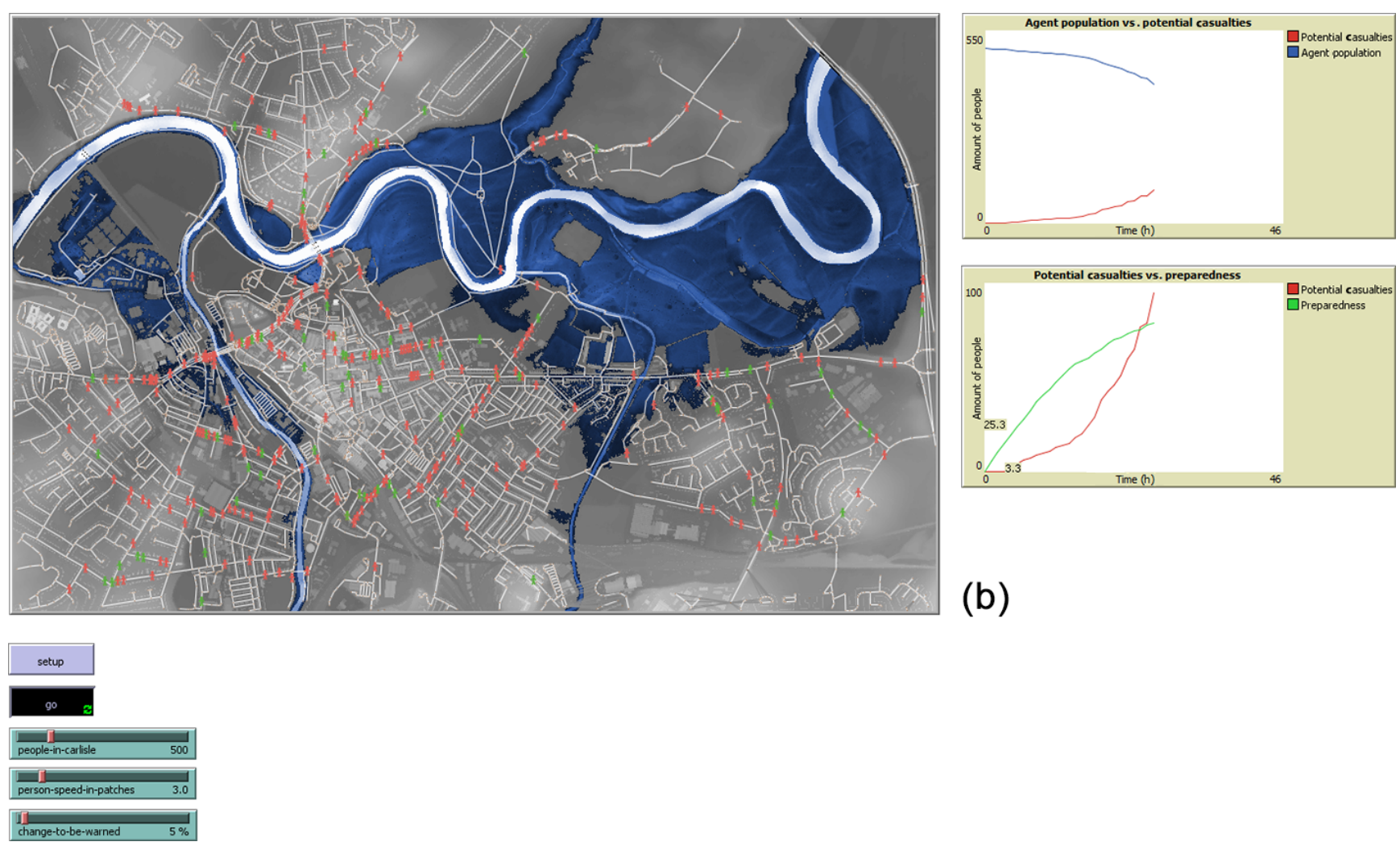

(b)

Figure A2. 

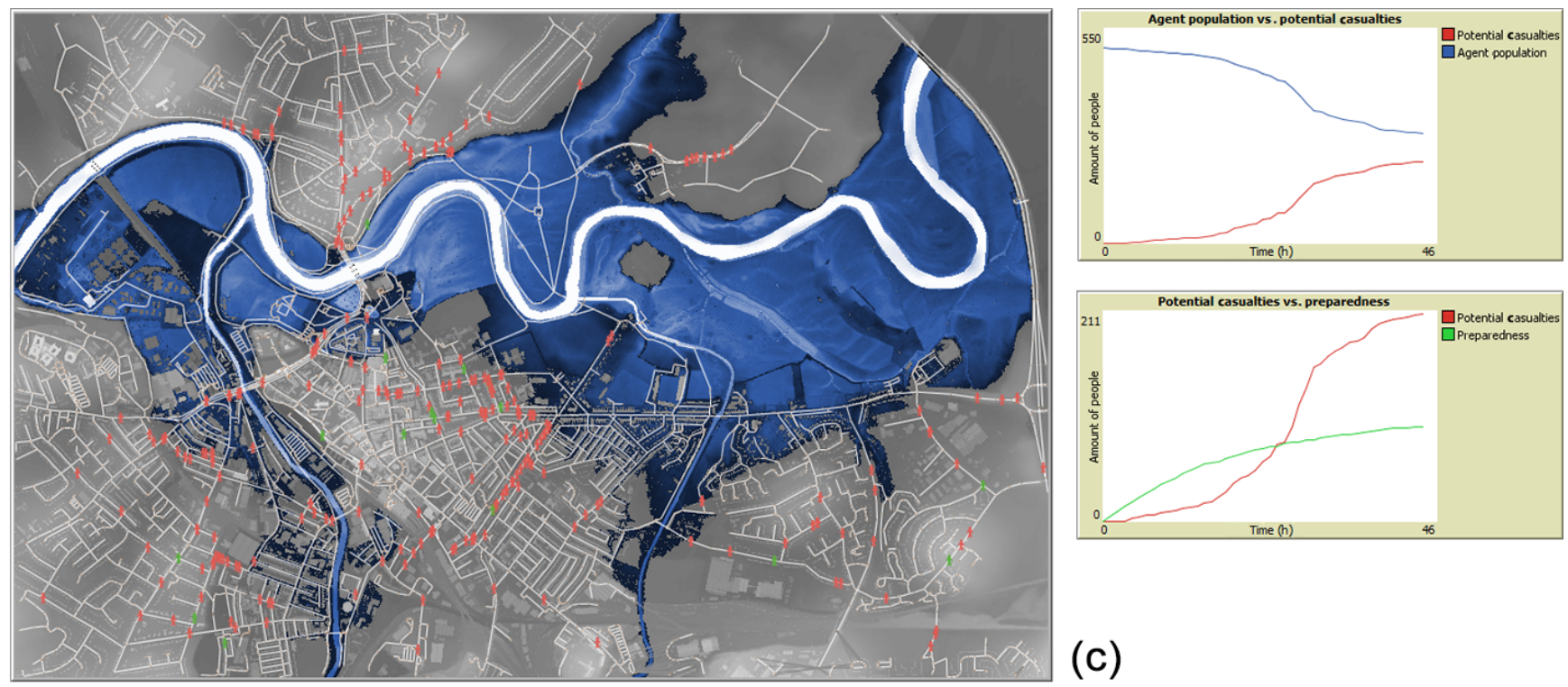

(c)

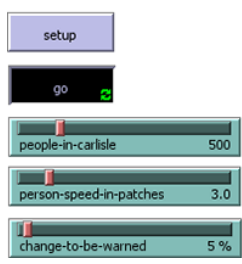

Figure A2. (a) An overview of the preliminary HABM. Shown here as an example are agents engaging in the daily routine (green) prior to the initiation of the LISFLOOD-FP flood inundation. Figures A2a to c represent only a small proportion $(<1000$ agents $)$ of the full agent populations ( $\sim 108000$ agents) simulated in the final model run. (b) Agents marked in red have become aware of the incoming flood and are taking evacuative action. Changes in agent colour on the GUI (graphical user interface) indicate that members of the sample population are transitioning to a potential casualty as the flood encroaches on their vicinity but also that the likelihood of a casualty occurring will diminish over time as the message of preparedness diffuses through the population. (c) Further to preparedness and potential casualty, an indication of areas in which agents are likely to stay, areas from which they are most likely to move, and the areas through which they are most likely to pass may be observed within the HABM GUI. This is explicated further in Fig. 5. 
Total number of potential casulaties vs. the percentage of population pre-warned for Carlisle.

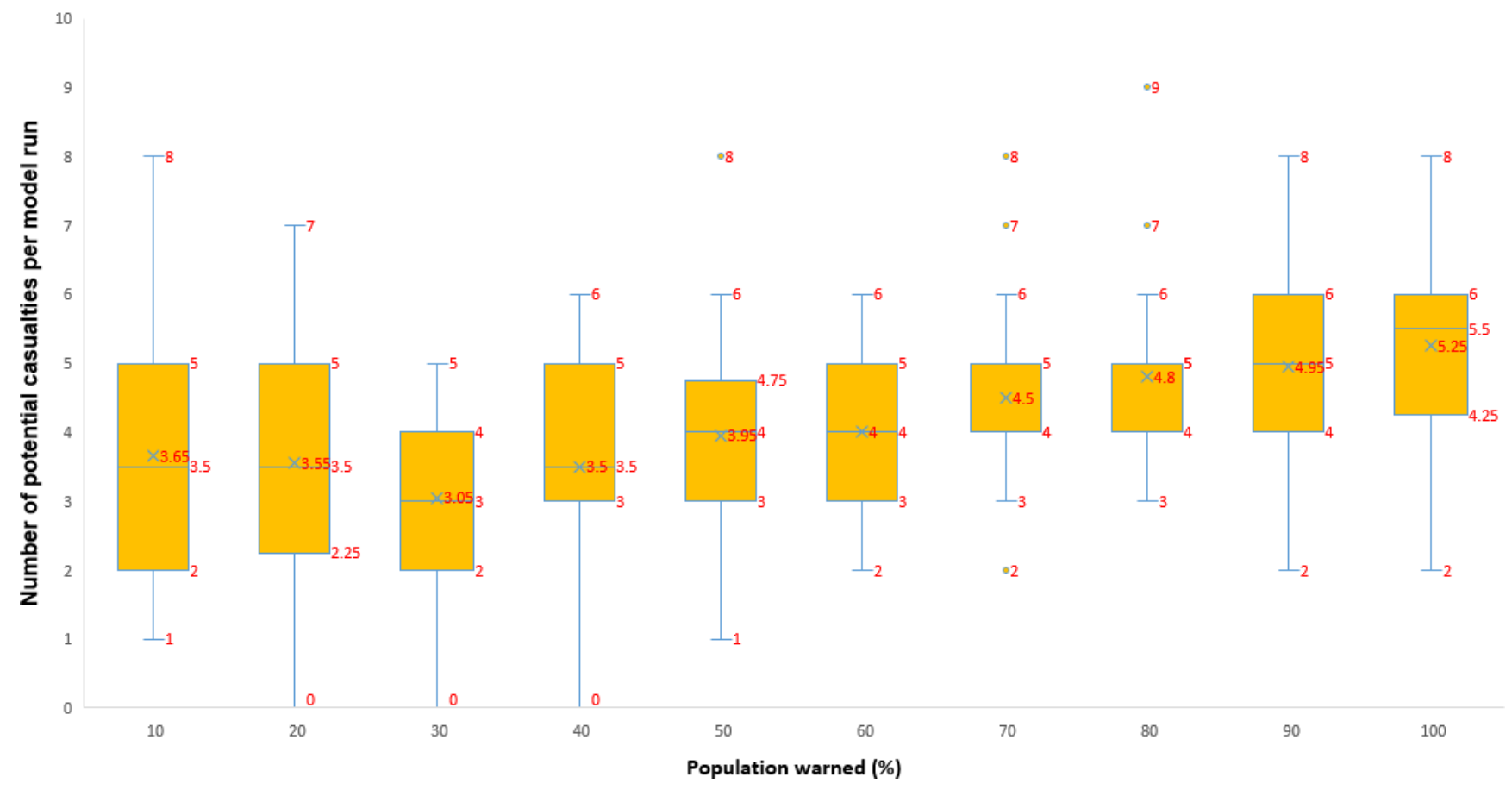

Figure A3. Box plot illustrating the range of values, sampled from 1000 agents (the most computationally stable sample size for batch runs on the available architecture) within the full agent population (108 000), for the total number of potential casualties vs. the percentage of the population pre-warned for Carlisle over 200000 simulations. 
Data availability. The population data were accrued and modified from the 2011 aggregate NOMIS (ONS) database found at https:// www.nomisweb.co.uk/census/2011/key_statistics (last access: January 2019) (NOMIS, 2019). This was cross-referenced with the supporting flow data found at https://wicid.ukdataservice.ac.uk/ (last access: January 2019) (ESRC, 2019). Building footprint data were taken from OSM, are copyrighted to OpenStreetMap contributors, and are available from https://osmbuildings.org/?lat=54.89485\& lon=-2.93623\&zoom $=16.0 \&$ tilt $=30$ (last access: March 2019) (Marsch, 2019). The LISFLOOD data set for Carlisle can be requested directly from Jeffrey Neal, and further details on the LISFLOOD-FP model are available at http://www.bristol.ac.uk/ geography/research/hydrology/models/lisflood/ (last access: December 2018) (Frank M. Bass Institute, 2018). Bass model curves were informed by information found on the Bass's Basement Research Institute website (@2008, 2009, 2010 Bass's Basement Research Institute) at https://ccl.northwestern.edu/netlogo/index.shtml (last access: April 2019) (Wilensky, 2019). The prototype Netlogo code for this model is currently still being used and modified as an active component of Thomas O'Shea's $\mathrm{PhD}$ thesis but it will be made available via the open-source repository on the NetLogo Modelling Commons website at http://modelingcommons.org/account/ login (last access: August 2020) (O'Shea and Haer, 2020) under the title of this paper.

Author contributions. TO wrote this paper with assistance and input from PB and JN.

Competing interests. The authors declare that they have no conflict of interest.

Special issue statement. This article is part of the special issue "Groundbreaking technologies, big data, and innovation for disaster risk modelling and reduction". It is not associated with a conference.

Acknowledgements. The authors are indebted to Toon Haer, and his colleagues at the IVM, VU Amsterdam; Nobuhito Mori and his colleagues at the Research Division of Atmospheric and Hydrospheric Disasters, DPRI, Kyoto; and our Bristol colleagues, Laurence Hawker and Jeison Sosa Moreno, for their helpful thoughts on the pre-developmental stages of the HABM concept.

Thomas O'Shea is supported by the EWS Educational Trust Exceptional Contribution Award, Paul Bates is supported by a Royal Society Wolfson Research Merit Award, and Jeffrey Neal is supported by a NERC fellowship for interdisciplinary research on flooding in Vietnam.

Financial support. This research has been supported by the EWS Educational Trust (grant no. 16-1-717/EDU341) and is affiliated with research conducted for the project entitled "An Interdisciplinary Approach to Understanding Past, Present and Future Flood Risk in Vietnam" under the Hydro-meterological Hazards in Vietnam programme (grant no. NE/S003061/1).
Review statement. This paper was edited by Carmine Galasso and reviewed by four anonymous referees.

\section{References}

Abebe, Y. A., Ghorbani, A., Nikoolic, I., Vojinovic, Z., and Sanchez, A.: A coupled flood-agent-institution modelling (CLAIM) framework for urban flood risk management, Environ. Model. Softw., 111, 483-492, 2019.

Alexander, C.: The Nature of Order: An Essay on the Art of Building and The Nature of the Universe, in: Book 1: The phenomenon of life, CES, Berkeley, CA, 1980.

Assaf, H. and Hartford, D. N. D.: A virtual reality approach to public protection and emergency preparedness planning in dam safety analysis, in: Proceedings of the Canadian dam association conference, Victoria, 2002.

Axelrod, R.: The Complexity of Cooperation: Agent-based models of competition and collaberation, Princeton University Press, Princeton, NJ, 1970.

Barendrecht, M., Viglione, A., and Blöschl, G.: A dynamic framework for flood risk, Water Security, 1, 3-11, https://doi.org/10.1016/j.wasec.2017.02.001, 2017.

Bass, F. M.: A new product growth for model consumer durables, Manage. Sci., 15, 215-227, https://doi.org/10.1287/mnsc.15.5.215, 1969.

Bates, P. D. and De Roo, A. P. J.: A simple raster-based model for flood inundation simulation, J. Hydrol., 236, 54-77, https://doi.org/10.1016/S0022-1694(00)00278-X, 2000.

Bates, P. D., Horritt, M. S., and Fewtrell, T. J.: A simple inertial formulation of the shallow water equations for efficient twodimensional flood inundation modelling, J. Hydrol., 387, 33-45, https://doi.org/10.1016/j.jhydrol.2010.03.027, 2010.

Bennet, D. and Tang, W.: Representing Complex Adaptive Spatial Systems, University of Iowa, Iowa City, 2017.

Bernardini, G., Camilli, S., Quagliarini, E., and D'Orazio, M.: Flooding risk in existing urban environment: from human behavioural patterns to microscopic simulation model, in: Proceedings from the 9th International Conference on Sustainability in Energy and Buildings, SEB-17, 5-7 July 2017, Chania, Crete, Greece, Energy Procedia, 134, 131-140, 2017.

Borshchev, A. and Filippov, A.: From System Dynamics and Discrete Event to Practical Agent Based Modelling: Reasons, Techniques, Tools, in: Proceedings from the 22nd Int. Conference of the System Dynamics Society, 25-29 July 2004, Oxford, England, 2004.

Bresser-Pereira, L. C., Maravall, J. M., and Przeworski, A.: Economic Reforms in New Democracies: A Social-Democratic Approach, Cambridge University Press, Cambridge, UK, 1993.

Chen, X. and Zhan, F. B.: Agent-based modelling and simulation of urban evacuation: relative effectiveness of simulations and staged evacuation strategies, J. ORS, 59, 25-33, https://doi.org/10.1057/palgrave.jors.2602321, 2008.

Chu, T.-Q.: Agent-based models and machine learning in decison support systems, Lap Lambert Academic Publishing, Paris, 2015.

Coates, G., Hawe, G. I., Wright, N. G., and Ahilan, S.: Agent-based modelling and inundation prediction to enable the identification of businesses affected by flooding, WIT Transact. Ecol. Environ., 184, 13-22, 2014. 
Correia, F. N., Rego, F., Saraiva, M. G. and Ramos, I.: Coupling GIS with Hydrologic and Hydraulic Flood Modelling, Water Resour. Manage., 12, 229-249, https://doi.org/10.1023/A:1008068426567, 1998a.

Correia, F. N., Fordham, M., Da Graca Raravia, M., and Bernado, F.: Flood Hazard Assessment and Management: Interface with the Public, Water Resour. Manage., 12, 209-227, 1998b.

Davies, S.: The Diffusion of Process Innovations, Cambridge University Press, Cambridge, 1979.

Dawson, R., Peppe, R., and Wang, M.: An agent based model for risk-based incident management of Natural Hazards, Nat. Hazards, 59, 167-189, 2011.

Dechter, R. and Pearl, J.: Generalised best-first search strategies and the optimality of $A^{*}$, J. ACM, 32, 505-536, 1986.

DEFRA, EA, and Coastal Erosion Risk Management R \& D Programme: Risk assessment for flood incident management: framework \& tools, Environment Agency, Bristol, 2007.

De Groot, J. I. M. and Schuitema, G.: How to make the unpopular popular? Policy characteristics, social norms and the acceptability of environmental policies, Environ. Sci. Policy, 19-20, 100107, https://doi.org/10.1016/j.envsci.2012.03.004, 2012.

Du, E., Cai, X., Sun, Z., and Minsker, B.: Exploring the Role of Social Media and Individual Behaviours in Flood Evacuation Processes: An Agent-Based Modeling Approach, Water Resour. Res., 53, 9164-9180, https://doi.org/10.1002/2017WR021192, 2017.

Dugdale, J., Saoud, N. B.-B., Pavard, B., and Pallamin, N.: Simulation and Emergency Management, in: Information Systems for Emergency Management, edited by: Van de Walle, B. T., Sharp, London, 229-253, 2009.

Eberlen, J., Scholz, G., and Gagliolo, M.: Simulate this! An Introduction to Agent-Based Models and their Power to Improve your Research Practice, Int. Rev. Social Psychol., 30, 149-160, https://doi.org/10.5334/irsp.115, 2017.

Environment Agency: Risk assessment for flood incident management: Annex 4 Understanding and application of complex system risk assessment models, Environment Agency, Bristol, 2006.

Environment Agency: Flooding - Minimising the risk, Environment Agency, Bristol, 2012.

Environment Agency: Creating a better place; Carlisle: Flood Investigation Report, Environment Agency, Bristol, 2016.

ESRC: RFO3EW - Location of usual residence and place of work, available at: https://wicid.ukdataservice.ac.uk/, last access: January 2019.

Fordham, M. H.: Ph.D. Thesis: Choice and Constraint in Flood Hazard Mitigation: The Environmental Attitudes of Floodplain residents and Engineers, Middlesex University Research Repository, London, available at: http://eprints.mdx.ac.uk/6430/ (last access: August 2020), 1992.

Frank M. Bass Institute: The Bass Model, available at: http://www. bristol.ac.uk/geography/research/hydrology/models/lisflood/, last access: December 2018.

Gilbert, N. and Troitzsch, K.: Simulation for the social scientist, 2nd Edn., Open University, Milton Keynes, 2005.

Gilligan, J. M., Brady, C., Camp, J. V., Nay, J. J., and Sengupta, P.: Participatory Simulations of Urban Flooding for Learning and Decision Support, in: Proceedings of the 2015 Winter Simulation Conference, Vanderbilt University Press, Nashville, TN, p. 2, 2015.
Guo, D., Ren, D., and Wang, C.: Integrated Agent Based Modeling with GIS for Large Scale Emergency Simulation, in: Advances in Computation and Intelligence, ISICA 2008, Lecture Notes in Computer Science, vol. 5370, edited by: Kang, L., Cai, Z., Yan, X., and Liu, Y., Springer, Berlin, Heidelberg, https://doi.org/10.1007/978-3-540-92137-0_68, 2008.

Guyot, P. and Honiden, S.: Agent-based participatory simulations: Merging multi-agent systems and role-playing games, Artific. Soc. Social Simul., 9, 35-39, 2006.

Haer, T., Wouter Botzen, W. J., Jeroen Aerts, C. J. H.: The effectiveness of flood risk communication strategies and the influence of social networks - Insights from an agent-based model, Environ. Sci. Policy, 60, 44-52, https://doi.org/10.1016/j.envsci.2016.03.006, 2016a.

Haer, T., Wouter Botzen, W. J., de Moel, H., and Jeroen Aerts, C. J. H.: Integrating Household Risk Mitigation Behaviour in Flood Risk Analysis: An Agent-Based Model Approach, Risk Anal.,, 37, 1977-1992, https://doi.org/10.1111/risa.12740, 2016b.

Hart, P. E., Nilsson, N. J., and Raphael, B. A.: A formal basis for the heuristic determination of minimum cost paths, IEEE Trans. Syst. Sci., 4, 100-107, https://doi.org/10.1109/TSSC.1968.300136, 1968.

Holland, J.: Complexity, Oxford University Press, Oxford, 2014.

Hornor, M. S.: Diffusion of Innovation Theory, Austin, Texas, USA, available at: http://www.disciplewalk.com/files/Marianne S_Hornor.pdf (last access: August 2020) 1998.

Horritt, M. S., Bates, P. D., Fewtrell, T. J., Mason, D. C., and Wilson, M. D.: Modelling the hydraulics of the Carlisle 2005 flood event, Proc. ICE - Water Manage., 163, 273-281, https://doi.org/10.1680/wama.2010.163.6.273, 2010.

Hunter, N. M., Bates, P. D., Neelz, S., Pender, G., Villanueva, I., Wright, N. G., Liang, D., Falconer, R. A., Lin, B., Waller, S., Crossley, A. J., and Martin, D. C.: Benchmarking 2D hydraulic models for urban flood simulations, Water Manage., 161, 13-30, https://doi.org/10.1680/wama.2008.161.1.13, 2008.

IPCC: Climate Change 2014: Synthesis Report, in: Contribution of Working Groups I, II and III to the Fifth Assessment Report of the Intergovernmental Panel on Climate Change, IPCC, Geneva, 2014.

Jakkola, H.: Comparison and Analysis of Diffusion Models, in: Diffusion and Adoption of Information Technology, edited by: Kurtz, K. and Preis-Heje, J., Springer Science \& Business Media, Dordrecht, 60-70, 1996.

Jongman, B.: Effective adaptation to rising flood risk, Nat. Commun., 9, 1-3, https://doi.org/10.1038/s41467-018-04396-1, 2018.

Kinzig, A. P., Ehrlich, P. R., Alston, L. J., Arrow, K., Barrett, S., Buchman, T. G., Daily, G. C., Levin, S., Oppenheimer, M., Ostrom, E., and Saari, D.: Social Norms and Global Environmental Challenges: The Complex Interaction of Behaviours, Values, and Policy, BioSciences, 1, 164-175, https://doi.org/10.1525/bio.2013.63.3.5, 2013.

Kossiakoff, A. and Sweet, W. N.: System Engineering Principles and Practice, Wiley, Washington, 2002.

Landstrom, C., Whatmore, S. J., and Lane, S. N.: Computer Simulation Modelling for Flood Risk Management in England, Sci. Stud., 24, 3-22, 2011. 
Larsen, G. D.: Horses for courses: relating innovation diffusion concepts to the stages of diffusion process, J. Construct. Manage. Econ., 23, 787-792, 2005.

Liu, J., Mooney, H., Hull, V., Davis, S. J., Gaskell, J., Hertel, T., Lubchenco, J., Seto, K. C., Gleick, P., Kremen, C., and Shuxin, L.: Systems integration for global sustainability, Science, 347, https://doi.org/10.1126/science.1258832, 2015.

Lumbroso, D. M., Sakamotoo, D., Johnsone, W. M., Tagg, A. F., and Lence, B. J.: The development of a Life Safety Model to settimate the risk posed to people by dam failures and floods, Dams Reserv., 21, 31-43, https://doi.org/10.1680/dare.2011.21.1.31, 2011.

Mahajan, V., Muller, E., and Bass, F. M.: New Product Diffusion Models in Marketing: A Review and Directions for Research, J. Market., 54, 1-26, https://doi.org/10.2307/1252170, 1990.

Marsch, J.: OSM Buildings, available at: https://osmbuildings.org/ ?lat $=54.89485 \&$ lon $=-2.93623 \&$ zoom $=16.0 \&$ tilt $=30$, last access: February 2019.

Massiani, J. and Gohs, A.: The Choice of Bass model coefficients to forecast diffusion for innovative products: An empirical investigation for new automotive technologies, Res. Transport. Econ., 50, 17-28, https://doi.org/10.1016/j.retrec.2015.06.003, 2015.

Medina, N., Sanches, A., and Vojinovic, Z.: The potential of Agent Based Models for Testing City Evacuation Strategies Under a Flood Event, Procedia Eng., 154, 765-772, doi10.1016/j.proeng.2016.07.581, 2016.

Morss, R. E., Mulder, K. J., Lazo, J. K., and Demuth, J. L.: How do People perceive, understand, and anticipate responding to flash flood risk warnings? Results from a public survey in Boulder, Colorado, USA, J. Hydrol., 541, 649-664, https://doi.org/10.1016/j.jhydrol.2015.11.047, 2016.

Mostafizi, A., Wang, H., and Dong, S.: Understanding the Multimodal Evacuation Behaviour for a NearField Tsunami, Transport. Res. Rec., 2673, 480-492, https://doi.org/10.1177/0361198119837511, 2019.

Müller, B., Bohn, F., Dreßler, G., Groeneveld, J., Klassert, C., Martin, R., and Schwarz, N.: Describing human decisions in agent-based models - ODD $+\mathrm{D}$, an extension of the ODD protocol, Environ. Model. Softw., 48, 37-48, https://doi.org/10.1016/j.envsoft.2013.06.003, 2013.

Namatame, A. and Chen, S.-H.: Agent-based modeling and network dynamics, Oxford University Press, Oxford, 2016.

Narzisi, G., Mysore, V., and Mishra, B.: Multi-Objective Evolutionary Optimisation of Agent-Based Models: An Application to Emergency Response planning, in: Proceedings from the second IASTED International Conference on Computational Intelligence, IASTED, San Francisco, 228-232, 2006.

Neal, J. C., Bates, P. D., Fewtrell, T. J., Hunter, N. M., Wilson, M. D., and Horritt, M. S.: Distrubuted whole city water level measurements from the Carlisle 2005 urban flood event and comparison with hydraulic model simulations, J. Hydrol., 268, 42-55, 2009.

Neal, J., Fewtrell, T., Bates, P., and Wright, N., A comparison of three parallelisation methods for 2D flood inundation models, Environ. Model. Softw., 25, 398-411, https://doi.org/10.1016/j.envsoft.2009.11.007, 2010.

Neal, J. C., Schumann, G., and Bates P. D.: A sub-grid channel model for simulating river hydraulics and floodplain inundation over large and data sparse areas, Water Resour. Res., 48, 1-16, https://doi.org/10.1029/2012WR012514, 2012.

Neal, J. C., Keef, C., Bates, P. D., Beven, K., and Leedal, D.: Probabilistic flood risk mapping including spatial dependence, Hydrol. Process., 27, 1349-1363, https://doi.org/10.1002/hyp.9572, 2013.

NetLogo: E. Center for connected learning and computer-based modeling, Northwestern University, Producer, available at: http: //ccl.northwestern.edu/netlogo/ (last access: 3 February 2017), 1999.

NOMIS: Census 2011, Key Statistics, available at: https://www. nomisweb.co.uk/census/2011/key_statistics, last access: January 2019.

Ormerod, P. and Rosewell, B.: Validation and Verification of Agent-Based Models in the Social Sciences, in: Epistemological Aspects of Computer Simulation in the Social Sciences, EPOS 2006, Lecture Notes in Computer Science, edited by: Squazzoni, F., Springer, Berlin, 130-140, 2009.

O'Shea, T. and Haer, T.: ABM for Flood Risk Warning, available at: http://modelingcommons.org/account/login, last access: August 2020.

Pyatkova, K., Chen, S. A., Butler, D., Vojinovic, Z., and Djordevic, S.: Assessing the knock-on effects of flooding on road transportation, J. Environ. Manage., 244, 48-60, 2019.

QGIS Development Team: QGIS Geographic Information System, Open Source Geospatial Foundation Project, available at: http: //qgis.osgeo.org, last access: August 2020.

Railsback, S. and Grimm, V.: Agent-Based and Individual-Based Modeling: A Practical Introduction, Princeton University Press, Princeton, NJ, 2012.

Rasmussen, J., Pejtersen, A. M., and Goodstein, L. P.: Cognitive systems Engineering, Wiley, London, 1994.

Roland, H. E. and Moriarty, B.: System Safety Engineering and Management, Wiley, Toronto, 1990.

Sabatier, P. A.: Top-down and bottom-up approaches to implementation research: a critical analysis and suggested synthesis, J. Publ. Policy, 6, 21-48, https://doi.org/10.1017/S0143814X00003846, 1986.

Sanders, P. and Sanders, F.: Spatial urban dynamics: A vision on the future of urban dynamics: Forrester revisited, Syst. Dynam. Rev., 1-32, 2004.

Smith, K. and Tobin, G. A.: Human Adjustment to the Flood Hazard, Longman, London, 1979.

Srbljinović, A. and Škunca, O.: An Introduction to Agent Based Modelling and Simulation of Social Processes, Interdisciplin. Descript. Complex Syst., 1, 1-8, 2003.

Sultan, F., Farley, J. U., and Lehmann, D. R.: Reflections on "A Meta-Analysis of Applications of Diffusion Models", J. Market. Res., 33, 247-249, 1996.

Tarde, G.: The laws of Imitation, H. Holt \& Co., New York, 1903.

UNISDR: Sendai Framework for Disaster Risk Reduction: 2015-2030, available at: https://www.undrr.org/publication/ sendai-framework-disaster-risk-reduction-2015-2030 (last access: April 2019), 2015.

Waldrop, W. W.: Complexity: The Emerging Science at the Edge of Order and Chaos, Simon \& Schuster, New York, 1993.

Wei, Y., Zhang, L., and Fan, Y.: SWARM based study on spatial-temporal emergence in flood, Keybernetes, 32, 870-880, https://doi.org/10.1108/03684920210443941, 2003. 
Werrity, A., Houston, D., Ball, T., Tavendale, A., and Black, A.: Exploring the Social Impacts of Flood Risk and Flooding in Scotland, University of Dundee, School of Social Sciences - Geography, University Press, Dundee, 2007.

Wheater, H. S.: Flood hazard and management a UK perspective, Philos. T. Roy. Soc., 364, 2135-2145, https://doi.org/10.1098/rsta.2006.1817, 2006.

Whitehead, A. N. and Russell, B.: Principia Mathematica, part 1: Mathematical Logic, 2009 Edn., Cambridge University Press, Cambridge, UK, p. 56, 1913.

Wilensky, U.: NetLogo, available at: https://ccl.northwestern.edu/ netlogo/index.shtml, April 2019

Wilensky, U. and Rand, W.: An Introduction to Agent-Based Modeling, MIT University Press, Cambridge, MA, 2015.

Wilson, M. D. and Atkinson, P. M.: The use of elevation data in flood inundation modelling: A comparison of ERS interferometric SAR and combined contour and differential GPS data, Int. J. River Basin Manage., 3, 3-20, https://doi.org/10.1080/15715124.2005.9635241, 2005.
Wisner, B., Blaikie, P., Cannon, T., and Davis, I.: At Risk: Natural Hazards, People's Vulnerability and Disasters, Routledge, London, 1994.

Wong, K. H. L. and Luo, M.: Computational tool in infrastruture emergency total evacuation analysis, in: Intelligence and security informatics, edited by: Kantour, P. E., Springer, Berlin, 27-34, 2005.

Zarboutis, N. and Marmaras, N., Investigating crowd behaviour during emergency evacuations using agent-based modelling, in: Proceedings of EAM, EAM, Athens, 17-19, 2005.

Zupančič, A.: Ethics of the Real: Kant, Lacan, Verso, London, 2000. 